\title{
A Polarimetric Analysis of Ice Microphysical Processes in Snow, Using Quasi-Vertical Profiles
}

\author{
ERICA M. GRIFFIN \\ Cooperative Institute for Mesoscale Meteorological Studies, University of Oklahoma, and NOAA/OAR \\ National Severe Storms Laboratory, and School of Meteorology, University of Oklahoma, Norman, Oklahoma \\ TERry J. SCHUUR AND ALEXANDER V. RYZHKOV \\ Cooperative Institute for Mesoscale Meteorological Studies, University of Oklahoma, and NOAA/OAR \\ National Severe Storms Laboratory, Norman, Oklahoma
}

(Manuscript received 8 February 2017, in final form 18 September 2017)

\begin{abstract}
This study implements a new quasi-vertical profile (QVP) methodology to investigate the microphysical evolution and significance of intriguing winter polarimetric signatures and their statistical correlations. QVPs of transitional stratiform and pure snow precipitation are analyzed using WSR-88D S-band data, alongside their corresponding environmental thermodynamic High-Resolution Rapid Refresh model analyses. QVPs of $K_{\mathrm{DP}}$ and $Z_{\mathrm{DR}}$ are implemented to demonstrate their value in interpreting elevated ice processes. Several fascinating and repetitive signatures are observed in the QVPs for differential reflectivity $Z_{\mathrm{DR}}$ and specific differential phase $K_{\mathrm{DP}}$, in the dendritic growth layer (DGL), and at the tops of clouds. The most striking feature is maximum $Z_{\mathrm{DR}}$ (up to $6 \mathrm{~dB}$ ) in the DGL occurring near the -10 -dB $Z Z_{H}$ contour within low $K_{\mathrm{DP}}$ and during shallower and warmer cloud tops. Conversely, maximum $K_{\mathrm{DP}}$ (up to $0.3^{\circ} \mathrm{km}^{-1}$ ) in the DGL occurs within low $Z_{\mathrm{DR}}$ and during taller and colder cloud tops. Essentially, $Z_{\mathrm{DR}}$ and $K_{\mathrm{DP}}$ in the DGL are anticorrelated and strongly depend on cloud-top temperature. Analyses also show correlations indicating larger $Z_{\mathrm{DR}}$ within lower $Z_{H}$ in the DGL and larger $K_{\mathrm{DP}}$ within greater $Z_{H}$ in the DGL. The high- $Z_{\mathrm{DR}}$ regions are likely dominated by growth of a mixture of highly oblate dendrites and/or hexagonal plates, or prolate needles. Regions of high $K_{\mathrm{DP}}$ are expected to be overwhelmed with snow aggregates and crystals with irregular or nearly spherical shapes, seeded at cloud tops. Furthermore, QVP indications of hexagonal plate crystals within the DGL are verified using in situ microphysical measurements, demonstrating the reliability of QVPs in evaluating ice microphysics in upper regions of winter clouds.
\end{abstract}

\section{Introduction}

Winter precipitation events, particularly transitional storms and heavy snow, are difficult to accurately forecast and nowcast, largely because of poor parameterization of ice microphysical processes in numerical weather prediction models. Given that snow properties (e.g., aspect ratios and bulk densities) vary significantly both temporally and spatially within clouds and also that ice particles are nonspherical, polarimetry is a valuable means to estimate bulk properties of snowstorms (Ryzhkov et al. 1998). With the recent polarimetric upgrade to the U.S. Weather Surveillance Radar-1988 Doppler (WSR-88D) network, dual-polarization data are now available for

Corresponding author: Erica M. Griffin, erica.griffin@noaa.gov observing the microphysical properties of winter precipitation in regions of the country never before sampled by polarimetric radar. Since polarimetric precipitation observations provide valuable information on the size, shape, orientation, and phase of hydrometeors (e.g., Herzegh and Jameson 1992; Doviak and Zrnić 1993; Zrnić and Ryzhkov 1999; Straka et al. 2000; Kumjian 2013a,b,c), these data will advance the understanding of microphysical processes and the life cycle of ice particles as they nucleate, evolve, and fall through a cloud. In turn, this will improve the representation of ice crystal properties including size, shape, density, and temperature dependence in future cloud microphysical models. This is important, since ice crystal habits are particularly sensitive to even slight changes in thermodynamic conditions and ice supersaturation (e.g., Bailey and Hallett 
2009), which can influence precipitation rates at the surface.

Specific differential phase $\left(K_{\mathrm{DP}}\right)$ observations in winter precipitation are particularly valuable for assessing ice content in the upper levels of clouds (e.g., Vivekanandan et al. 1994; Ryzhkov et al. 1998; Kennedy and Rutledge 2011). The most pronounced polarimetric radar signatures occur in the dendritic growth layer (DGL; i.e., between $-10^{\circ}$ and $-20^{\circ} \mathrm{C}$ ) and at the tops of clouds, while aggregation and riming processes dissolve prominent differential reflectivity $\left(Z_{\mathrm{DR}}\right)$ signatures below. Intriguing $Z_{\mathrm{DR}}$ and $K_{\mathrm{DP}}$ signatures above the melting layer (ML) have been documented in previous studies, demonstrating polarimetric indications of dendrites and plate-like ice crystals in the DGL (e.g., Ryzhkov and Zrnić 1998; Ryzhkov et al. 1998; Wolde and Vali 2001; Kennedy and Rutledge 2011; Bechini et al. 2013; Andrić et al. 2013; Griffin et al. 2014; Williams et al. 2015; Schrom et al. 2015; Kumjian and Lombardo 2017), and a variety of ice habits generated as primary ice at the top of clouds, for example, in generating cells (e.g., Kumjian et al. 2014).

Ryzhkov et al. (1998) documented a pronounced elevated region of high $K_{\mathrm{DP}}$, centered at a height of $6 \mathrm{~km}$, within a trailing precipitation region of a squall line, and Ryzhkov and Zrnić (1998) found peak $K_{\mathrm{DP}}$ of $0.35^{\circ} \mathrm{km}^{-1}$ at $S$ band at $5 \mathrm{~km}$, in a warm snow storm that contained heavily aggregated snow. Later, Kennedy and Rutledge (2011) reported on S-band measurements of an elevated layer of $K_{\mathrm{DP}}$ in four Colorado winter storms that had local maxima of $\sim 0.15^{\circ}-0.4^{\circ} \mathrm{km}^{-1}$ near the $-15^{\circ} \mathrm{C}$ isotherm. They further showed that the passage of these regions was associated with an increase in surface precipitation. Calculations using an electromagnetic scattering model indicated that highly oblate spheroidal particles with diameters between $\sim 0.8$ and $1.2 \mathrm{~mm}$ in range and moderate ice densities produced $K_{\mathrm{DP}}$ values that were consistent with radar observations. Their calculations were unable to reproduce $Z_{\mathrm{DR}}$, however. They further concluded that the persistent collocation of this signature with the $-15^{\circ} \mathrm{C}$ isotherm was an indication that rapidly growing dendrites likely played a significant role in producing the elevated $K_{\mathrm{DP}}$ signature. In another study of winter storms, Andrić et al. (2013) reported on isolated pockets of enhanced $K_{\mathrm{DP}}$ and $Z_{\mathrm{DR}}$ that were collocated with reduced crosscorrelation coefficient $\left(\rho_{\mathrm{hv}}\right)$. These signatures were also found to be located at temperatures between $-10^{\circ}$ and $-15^{\circ} \mathrm{C}$, and were coincident with a zone of large radar reflectivity vertical gradient, with reflectivity factor $Z_{H}$ increasing toward the ground. Using a simple kinematical, one-dimensional, two-moment bulk microphysical model that was coupled with an electromagnetic scattering model, Andrić et al. (2013) were able to approximately reproduce the correct profile types of vertical dependencies and magnitudes of $Z_{H}$ and $\rho_{\mathrm{hv}}$ and the correct profiles (but not magnitudes) of $Z_{D \mathrm{R}}$ and $K_{\mathrm{DP}}$. They concluded that their inability to reproduce the correct profiles and magnitudes of all of the signatures indicated that microphysical processes not included in the model, such as secondary ice production, were likely important factors in producing the observed signature. Bechini et al. (2013) also documented enhanced $Z_{\mathrm{DR}}$ and $K_{\mathrm{DP}}$ values near the model-indicated $-15^{\circ} \mathrm{C}$ isotherm in the ice region of precipitating clouds, using $\mathrm{C}$ - and X-band radars in northwestern Italy. They found that these regions of enhancement $\left(K_{\mathrm{DP}}\right.$ values peaked at around $2.0^{\circ} \mathrm{km}^{-1}$ at $\mathrm{C}$ band) were likely associated with dendritic growth and were correlated with the $Z_{H}$ below. Furthermore, Griffin et al. (2014) observed that DGLs near the model-predicted $-15^{\circ} \mathrm{C}$ isotherm were correlated with increased snowfall and large $Z_{H}$ near the surface in a historic northeastern blizzard, bolstering the results of Bechini et al. (2013), Andrić et al. (2013), and Kennedy and Rutledge (2011).

In a more recent study, Schrom et al. (2015) documented X-band observations of these enhanced $K_{\mathrm{DP}}$ signatures near $-15^{\circ} \mathrm{C}$, with $Z_{\mathrm{DR}}$ decreasing and $Z_{H}$ increasing toward the ground (indicating aggregation or riming), within several Colorado winter storms. They retrieved particle size distributions of dendrites and plates, demonstrating that enhancements in $Z_{\mathrm{DR}}$ can likely indicate both plates and dendrites. Similarly, Wolde and Vali (2001) reported hexagonal plates, stellars, and dendrites occurring within large $Z_{\mathrm{DR}}$ near the $-15^{\circ} \mathrm{C}$ isotherm. To help identify regions of likely icing hazards, Williams et al. (2015) identified two categories of enhanced $Z_{\mathrm{DR}}$ in winter and summer stratiform systems. In one category, $Z_{\mathrm{DR}}$ between 0 and $3 \mathrm{~dB}$ occur in larger $Z_{H}$ (i.e., $10-30 \mathrm{~dB} Z$ ) when dendrites are present among supercooled water and water-saturated environments, at temperatures between $-10^{\circ}$ and $-20^{\circ} \mathrm{C}$. They described how this region can potentially produce hazardous icing conditions for aircraft. In their second category, flat-plate and dendritic crystals are associated with $Z_{\mathrm{DR}}$ between 3 and $7 \mathrm{~dB}$, in areas of lower $Z_{H}$ (i.e., from -10 to $10 \mathrm{~dB} Z$ ) near the tops of clouds. In this region, they found evidence of diffusional growth of the highaspect-ratio ice crystals, within minimal or absent amounts of supercooled water, therefore posing no icing hazards.

From a different perspective, Moisseev et al. (2015) suggested that layers of $K_{\mathrm{DP}}$ near the $-15^{\circ} \mathrm{C}$ isotherm can rather be attributed to the onset of aggregation, occurring within high concentrations of ice, because of a seeder-feeder process. They also proposed that when layers of enhanced $Z_{\mathrm{DR}}$ occur near the $-15^{\circ} \mathrm{C}$ isotherm 
within minimal $K_{\mathrm{DP}}$, and within low concentrations of ice, crystal growth is likely to be the main microphysical process, explaining why layers of maximum $K_{\mathrm{DP}}$ and $Z_{\mathrm{DR}}$ may not always be temporally collocated. Additionally, Kumjian and Lombardo (2017) documented that layers of enhanced $K_{\mathrm{DP}}$ are correlated with greater radar-inferred ascent near the $-15^{\circ} \mathrm{C}$ isotherm, and that enhanced $K_{\mathrm{DP}}$ occurs more often in regions of greater supersaturations, with increased $Z_{H}$ and heavier snowfall near the surface. Overall, these studies have established important building blocks toward a more thorough understanding of these polarimetric signatures and their implications, however, more polarimetric and in situ analyses are needed to better diagnose the ice processes that govern the evolution of winter clouds and precipitation.

Recently, a new method of processing and displaying polarimetric radar data has been developed, providing an opportunity to better elucidate ice microphysical processes and their temporal evolution. Ryzhkov et al. (2016) introduced a quasi-vertical profile (QVP) methodology in which $Z_{H}, Z_{\mathrm{DR}}, \rho_{\mathrm{HV}}$, and differential phase $\Phi_{\mathrm{DP}}$ from weather surveillance radars are azimuthally averaged at relatively high antenna elevation angles exceeding $10^{\circ}-20^{\circ}$. Use of these high elevation angles reduces the effects of beam broadening and horizontal inhomogeneity (Ryzhkov et al. 2016). The resulting QVPs display the polarimetric variables in a convenient time-versus-height format, which allows for efficient investigation of key cloud microphysical processes. Ryzhkov et al. (2016) documented QVP examples to demonstrate advantages of the QVP technique, including the ability to compare polarimetric WSR-88D data with data from vertically looking remote sensors (e.g., wind profilers, lidars, and cloud radars), to continuously monitor the ML and DGL with high vertical resolution, and to potentially discriminate between rimed and aggregated snow. The QVP methodology has quickly become popular and has now been implemented by Kumjian and Lombardo (2017), who demonstrate the value of QVPs for providing knowledge on the microphysical and kinematic structures of Northeast winter storms. They are also the first to directly relate kinematic and microphysical information in winter storms, using WSR-88D QVPs of Doppler velocity and polarimetric variables, including $K_{\mathrm{DP}}$, to infer regions of mesoscale ascent.

Since January of 2013, we have compiled a database that consists of thousands of hours of polarimetric WSR$88 \mathrm{D}$ observations in a wide variety of winter precipitation events. Many of those datasets exhibit several intriguing, repetitive, and previously undocumented polarimetric signatures. In this study, we use QVPs produced from a few select events obtained from that database to investigate the microphysical evolution and significance of some of those. Radar data and their microphysical interpretation are presented in context of the thermodynamic environment provided by a numerical model with data extracted from the QVPs, to document statistical correlations between cloud-top temperature (CTT) and $K_{\mathrm{DP}}$ and $Z_{\mathrm{DR}}$ in the DGL between $-10^{\circ}$ and $-20^{\circ} \mathrm{C}$.

\section{QVP methodology}

QVPs provide an unprecedented look into the microphysical processes within winter storms and are an efficient way to process and analyze polarimetric WSR-88D data. This investigation builds on the work of Ryzhkov et al. (2016) by demonstrating the value of using QVPs of $K_{\mathrm{DP}}$ and $Z_{\mathrm{DR}}$ to examine the temporal evolution of ice microphysical processes in winter clouds and precipitation. The $K_{\mathrm{DP}}$ signatures contain important information about ice microphysics aloft and are particularly useful for the quantification of ice. Ryzhkov et al. (1998) documented two methods of ice water content (IWC) estimation that define IWC either as a function of $K_{\mathrm{DP}}$ and $Z_{\mathrm{DR}}$, or as a function of $K_{\mathrm{DP}}$. The IWC- $K_{\mathrm{DP}}-Z_{\mathrm{DR}}$ algorithm is particularly useful when estimating IWC in DGLs, where $Z_{\mathrm{DR}}$ can be large, and the IWC- $K_{\mathrm{DP}}$ algorithm is applicable for regions of low $Z_{\mathrm{DR}}$. They found the polarimetric methods outperform the conventional IWC- $Z_{H}$ methods. Accordingly, there is ample potential for $K_{\mathrm{DP}}$ and $Z_{\mathrm{DR}}$ measurements to improve upon existing radar-based techniques to estimate IWC in snow.

The QVP methodology, described in Ryzhkov et al. (2016), assumes a certain degree of horizontal homogeneity of the atmosphere, particularly at higher altitudes (Table 1). Kaltenboeck and Ryzhkov (2017) demonstrated that the horizontal resolution of QVPs retrieved from data collected at antenna tilts of $10^{\circ}-20^{\circ}$ is sufficient to monitor the passage of mesoscale frontal boundaries associated with cold season transitional events. It should also be noted that in the QVP methodology, the averaging does not include azimuths that contain no data.

The procedure for generating QVPs of $K_{\mathrm{DP}}$, however, was not specified in Ryzhkov et al. (2016) and requires explanation herein. Radial profiles of $\Phi_{\mathrm{DP}}$ at each azimuth are used to generate radial profiles of $K_{\mathrm{DP}}$ as described elsewhere (e.g., Ryzhkov et al. 2005). Then, QVPs of $K_{\mathrm{DP}}$ are obtained by azimuthal averaging of radial $K_{\mathrm{DP}}$ profiles produced at each azimuth. The estimation of $K_{\mathrm{DP}}$ does not pose any problem for pure snow events but requires special processing in stratiform rain with bright bands because of strong contribution of the backscatter differential phase $\delta$ to the total 
TABLE 1. Horizontal and vertical resolutions of QVPs at two different antenna elevations (i.e., $10^{\circ}$ and $20^{\circ}$ ) and two heights above ground $(H)$, indicating resolutions near the $\mathrm{ML}(H=3 \mathrm{~km})$ and near the top of the cloud $(H=8 \mathrm{~km})$.

\begin{tabular}{|c|c|c|c|c|c|}
\hline \multirow[b]{2}{*}{ Elev } & \multicolumn{2}{|c|}{ Horizontal resolution } & \multicolumn{2}{|c|}{ Vertical resolution } & \multirow[b]{2}{*}{ Min heigh } \\
\hline & $H=3 \mathrm{~km}$ & $H=8 \mathrm{~km}$ & $H=3 \mathrm{~km}$ & $H=8 \mathrm{~km}$ & \\
\hline $\begin{array}{l}10^{\circ} \\
20^{\circ}\end{array}$ & $\begin{array}{l}34 \mathrm{~km} \\
165 \mathrm{~km}\end{array}$ & $91 \mathrm{~km}$ & $0.30 \mathrm{~km}$ & $0.79 \mathrm{~km}$ & $0.35 \mathrm{~km}$ \\
\hline
\end{tabular}

differential phase $\Phi_{\mathrm{DP}}$ in the ML (Trömel et al. 2014). Large $\delta$ (up to $80^{\circ}$ at $\mathrm{S}$ band) is clearly exhibited in the QVP of $\Phi_{\mathrm{DP}}$ (Ryzhkov et al. 2016; Fig. 1a) and has to be taken into account in the processing of $K_{\mathrm{DP}}$ in each individual radial. We use the following routine to avoid $\delta$ contamination in the estimation of $K_{\mathrm{DP}}$. A radial profile of $\Phi_{\mathrm{DP}}$ along a single ray is characterized by enhanced noisiness at range gates corresponding to the ML due to a sharp drop in $\rho_{\text {hv }}$ (Fig. 1b). Two criteria are used to recognize these range gates: $\rho_{\mathrm{hv}}$ is less than 0.9 and the texture parameter of $\Phi_{\mathrm{DP}}\left[\mathrm{SD}\left(\Phi_{\mathrm{DP}}\right)\right]$ is higher than $10^{\circ}$. Noisy values of $\Phi_{\mathrm{DP}}$ associated with the ML are removed from the raw $\Phi_{\mathrm{DP}}$ data and replaced by an interpolation line connecting valid (i.e., noncontaminated) values of $\Phi_{\mathrm{DP}}$ between the gates below and above the ML, as shown in Fig. 1b. The modified profile of $\Phi_{\mathrm{DP}}$ is then used to compute $K_{\mathrm{DP}}$ that is not contaminated by the contribution from the backscatter differential phase. This method also allows for roughly estimating "net" $K_{\mathrm{DP}}$ within the ML as a slope of the interpolation line in Fig. 1.

QVP results are dependent on the choice of antenna elevation angle. Theoretical dependencies of $Z_{\mathrm{DR}}$ and $K_{\mathrm{DP}}$ on elevation angle $\theta$ for oblate spheroidal hydrometeors are represented by the formulas

$$
\begin{aligned}
Z_{\mathrm{dr}}(\theta) & \approx \frac{Z_{\mathrm{dr}}(0)}{\left[Z_{\mathrm{dr}}^{1 / 2}(0) \sin ^{2} \theta+\cos ^{2} \theta\right]^{2}} \quad \text { and } \\
K_{\mathrm{DP}}(\theta) & \approx K_{\mathrm{DP}}(0) \cos ^{2} \theta .
\end{aligned}
$$

In Eq. (1), $Z_{\mathrm{dr}}(0)$ and $Z_{\mathrm{dr}}(\theta)$ represent linear scale differential reflectivities at elevation angles $0^{\circ}$ and $\theta^{\circ}$, respectively (Ryzhkov et al. 2005, 2016). In Eq. (2), $K_{\mathrm{DP}}(0)$ and $K_{\mathrm{DP}}(\theta)$ represent $K_{\mathrm{DP}}$ at elevation angles $0^{\circ}$ and $\theta^{\circ}$, respectively. According to Eqs. (1) and (2), the elevation dependencies of $Z_{\mathrm{DR}}$ and $K_{\mathrm{DP}}$ are relatively weak in the range of elevation angles between $10^{\circ}$ and $20^{\circ}$, as illustrated in Fig. 2 where QVPs generated at elevations $9.9^{\circ}$ and $19.5^{\circ}$ are compared. The differences between Figs. 2a-d and Figs. 2e-h are likely more related to differences in the averaging areas at the two elevations, rather than elevation dependencies of $Z_{\mathrm{DR}}$ and $K_{\mathrm{DP}}$.

\section{Data analysis}

In this section, QVPs of polarimetric WSR-88D variables at high elevation angles (i.e., $9.9^{\circ}-19.5^{\circ}$ ) are presented with their corresponding environmental thermodynamic analyses from the operational $3-\mathrm{km}$

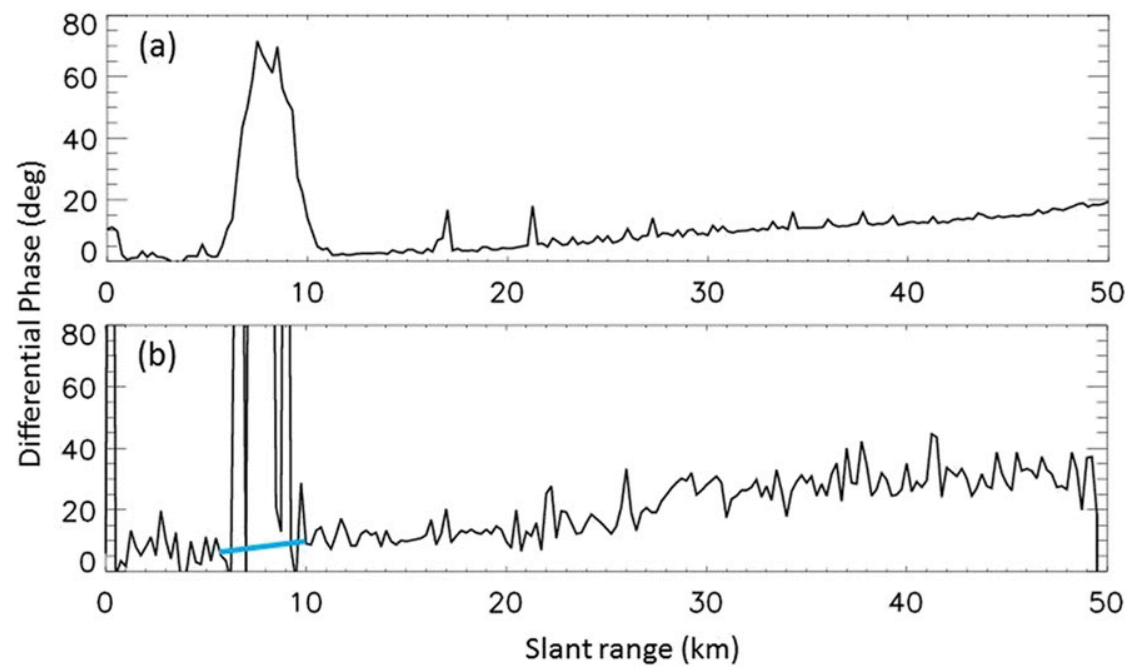

FIG. 1. Slant range vs (a) QVP of $\Phi_{\mathrm{DP}}$ and (b) $\Phi_{\mathrm{DP}}$ along the $220^{\circ}$ radial, for KDGX QVP data from 0252 through 0257 UTC $12 \mathrm{Feb} 2014$, at $10^{\circ}$ elevation. The blue-highlighted line represents the interpolated values of $\Phi_{\mathrm{DP}}$ between the gates below and above the ML. 

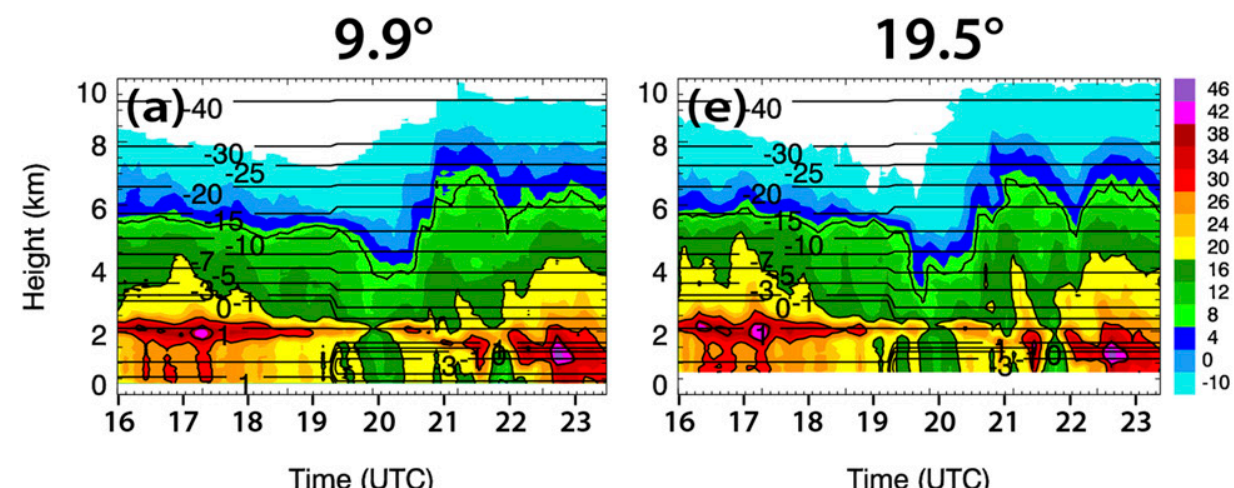

\section{$\mathbf{Z}_{\mathbf{H}}$ \\ (dBZ)}
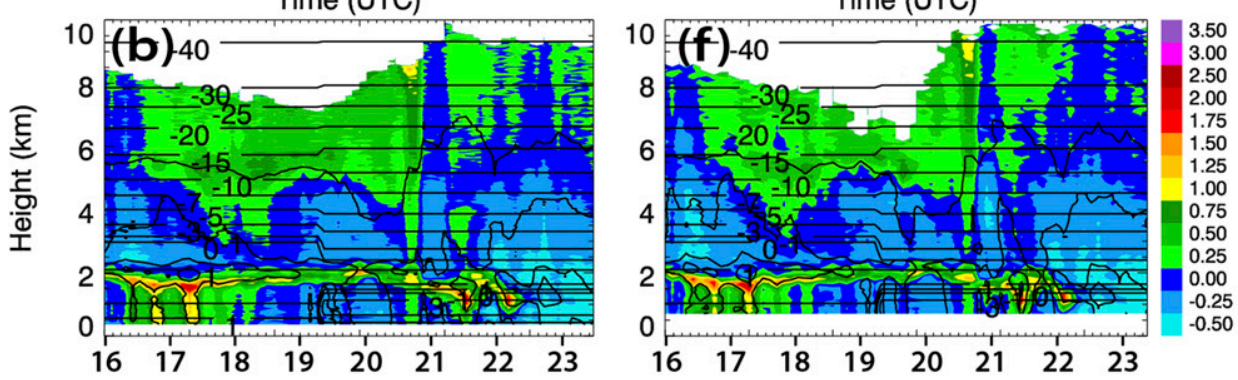

$\mathbf{Z}_{\mathrm{DR}}$

(dB)

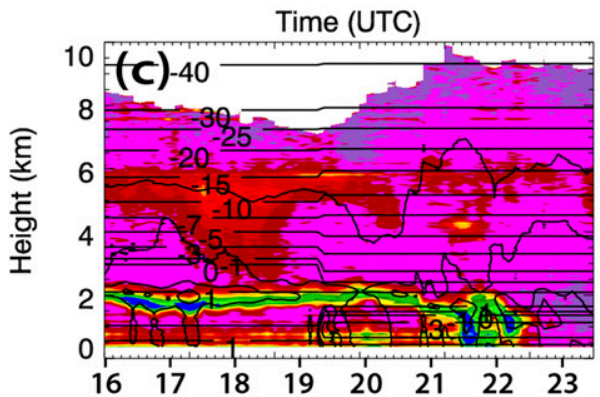

Time (UTC)

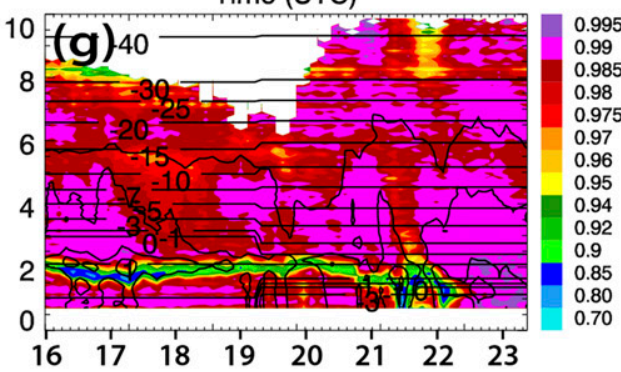

$\rho_{\mathrm{HV}}$
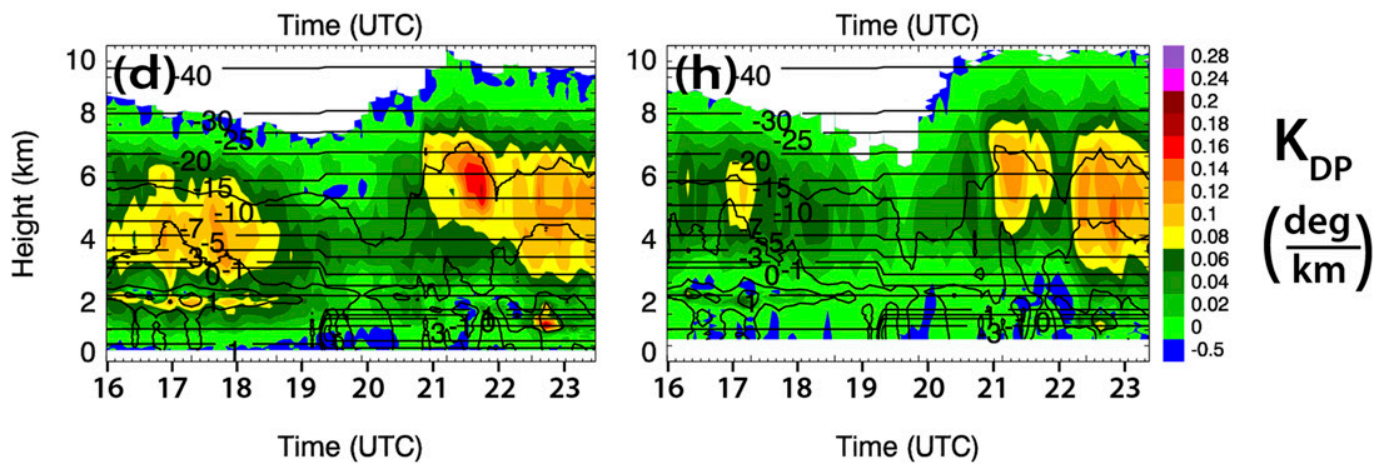

FIG. 2. Time-vs-height QVP of (a),(e) $Z_{H}$, (b),(f) $Z_{\mathrm{DR}}$, (c),(g) $\rho_{\mathrm{hv}}$, and (d),(h) $K_{\mathrm{DP}}$ from KLVX from 1600 through 2328 UTC 4 Mar 2015 at (left) $9.9^{\circ}$ and (right) $19.5^{\circ}$ elevation angles. Contours of HRRR model wet-bulb temperature $\left({ }^{\circ} \mathrm{C}\right)$ are overlaid in each plot. Also, in each QVP, $Z_{H}$ is contoured at $10,20,30$, and $40 \mathrm{~dB} Z$.

High-Resolution Rapid Refresh (HRRR; Smith et al. 2008; Benjamin et al. 2016) model overlaid. The selection of QVPs at varying elevation angles illustrates that data at $9.9^{\circ}$ are just as valuable as those at $19.5^{\circ}$. The model output are used to interpret the polarimetric signatures of ice crystal habits that form at different temperatures, ultimately helping to elucidate the relationship between the polarimetric signatures and ice microphysical processes within winter precipitation. Surface precipitation type observations from 5-min augmented Automated Surface Observing System (ASOS) sites and Meteorological Phenomena Identification Near the Ground 
(mPING; Elmore et al. 2014) are also used to aid in the interpretation of the approximate 5-min radar observations and provide verification of radar-indicated transitions in precipitation type at the surface.

Here, we present QVPs for five winter precipitation events to explore the evolution and significance of key ice microphysical processes in the upper levels of winter storms. The cases include one pure snow event and four transitional events, three of which occur within the same winter system over the southeastern United States. Though several repetitive signatures are observed, particularly in the $Z_{\mathrm{DR}}$ and $K_{\mathrm{DP}}$ profiles, this analysis focuses on a newly discovered recurring correlation between CTT (defined as the wet-bulb temperature at the uppermost level for which $Z_{H} \geq-10 \mathrm{~dB} Z$ is encountered) with $Z_{\mathrm{DR}}$ and $K_{\mathrm{DP}}$ signatures in DGLs.

\section{a. KEAX 1 February 2014 winter storm}

On 1 February 2014, a transitional winter storm passed over the KEAX WSR-88D (Pleasant Hill, Missouri) producing surface precipitation types that included ice pellets, freezing rain, and snow (mPING and ASOS observations). Figures 3a-d depict polarimetric QVPs of $Z_{H}, Z_{\mathrm{DR}}, \rho_{\mathrm{hv}}$, and $K_{\mathrm{DP}}$, at $12.5^{\circ}$ elevation from 0353 through 1630 UTC during this event. A distinct ML bright band, as is particularly evident in the $\rho_{\mathrm{hv}}$ profile, is indicated from 0546 through 1029 UTC. The most prominent feature in the QVPs, however, is a fascinating layer of enhanced $Z_{\mathrm{DR}}$ from 1029 through 1630 UTC that ranges from 1 to $>3.5 \mathrm{~dB}$ (maximum $Z_{\mathrm{DR}}$ of $5.1 \mathrm{~dB}$ at $\sim 1600$ UTC) between heights of approximately 3 and $5 \mathrm{~km}$. This layer of enhanced $Z_{\mathrm{DR}}$ occurs during a period that follows the largest $Z_{H}$ near the surface, within low $Z_{H}$ from -10 to $-12 \mathrm{~dB} Z, \rho_{\mathrm{hv}}$ as low as 0.92 , and a period during which the cloud-top height drops from approximately $8 \mathrm{~km}$ to $5 \mathrm{~km}$. During this period, we believe ice crystals falling out of the upper cloud layer completely sublimate within a midlevel layer of dry air that lies immediately above the layer of high $Z_{\mathrm{DR}}$.

In this study, CTT is defined at the first occurrence of $-10 \mathrm{~dB} Z$, beginning at the top of the grid and using a top-down methodology. It should be noted that, because of the presence of the dry layer, this event requires additional criteria for defining cloud top. To extract CTTs for this event (with respect to microphysical analysis of the QVPs), we use a methodology that seeks to find the cloud top that falls immediately below the midlevel layer of dry air. The top-down methodology therefore begins in the midlevel dry layer where $Z_{H}<-10 \mathrm{~dB} Z$ and requires that at least three consecutive (in order to eliminate false tops that might result from additional gaps in the data) levels of $Z_{H} \geq-10 \mathrm{~dB} Z$ are encountered before a secondary, lower-level cloud top can be defined. Below the dry layer, ice condensation nuclei are likely activated at temperatures between $-15^{\circ}$ and $-20^{\circ} \mathrm{C}$ in a layer that is saturated with respect to ice, and nearly saturated with respect to water, resulting in the generation of either hexagonal plate crystals or pristine dendrites, depending on humidity, that account for the high $Z_{\mathrm{DR}}$ signature.

To better understand the thermodynamic environment responsible for the observed signatures, we present the 1200 UTC 1 February 2014 thermodynamic sounding from Topeka, Kansas (Fig. 4), which is located $\sim 120 \mathrm{~km}$ west of the KEAX radar. In agreement with the interpretation presented above, this sounding reveals a layer of dry air at temperatures $<-20^{\circ} \mathrm{C}$ and heights between approximately 5 and $7 \mathrm{~km}$. This explains the absence of echo above the DGL in Fig. 3 during the period of high $Z_{\mathrm{DR}}$. Immediately below the dry layer, the sounding also indicates a layer that is slightly below water saturation with a mean DGL (indicated by the blue line between the $-10^{\circ}$ and $-20^{\circ} \mathrm{C}$ isotherms in Fig. 4) relative humidity of $88 \%$. Though subsaturated with respect to water, calculations using a first approximation for the saturation vapor pressure of ice $e_{i}(T)=A e^{-B / T}$ with $A=3.41 \times 10^{9} \mathrm{kPa}$ and $B=6.13 \times 10^{3} \mathrm{~K}$ (Rogers and Yau 1989) indicate that this moist layer was supersaturated with respect to ice by as much as $10 \%$. This supports the QVP results and provides quantitative validation that activation and growth of hexagonal plates or dendrites is likely in these ambient conditions.

Another prominent feature in the QVPs in Fig. 3 is an anticorrelation between maximum $K_{\mathrm{DP}}$ and maximum $Z_{\mathrm{DR}}$ in the DGL. Maximum $K_{\mathrm{DP}}$ in the DGL peaks at $0.24^{\circ} \mathrm{km}^{-1}$ just after $0800 \mathrm{UTC}$, within $Z_{H}$ between -10 and $20 \mathrm{~dB} Z$ and above the largest $Z_{H}$ near the surface. It is important to note that the $K_{\mathrm{DP}}$ maximum occurs during the period of lowest $Z_{\mathrm{DR}}$ in the DGL, and when cloud tops are tallest and coldest (approximately $-40^{\circ} \mathrm{C}$ ). Conversely, maximum $Z_{\mathrm{DR}}$ in the DGL occurs during the periods of lowest $K_{\mathrm{DP}}$ in the DGL and when cloud tops are shallower and warmer (from approximately $-15^{\circ}$ to $-20^{\circ} \mathrm{C}$ ). The low $K_{\mathrm{DP}}$ is a result of small ice concentrations, while the $Z_{\mathrm{DR}}$ of the rapidly growing particles does not depend on concentration. Anisotropic particles must have a sufficient concentration to result in larger $K_{\mathrm{DP}}$. There is also a notable decrease of $\rho_{\mathrm{hv}}$ in areas of the DGL where $Z_{\mathrm{DR}}$ is particularly high. This interdependence of $Z_{\mathrm{DR}}$ and $\rho_{\mathrm{hv}}$ in ice clouds is well known and reported in a number of studies (e.g., Melnikov and Straka 2013). The $\rho_{\text {hv }}$ of very anisotropic crystals (such as pristine dendrites, plates, and needles) is usually lower than that of quasispherical hydrometeors.

It is important to note that low reflectivities $(<0$ or even $-10 \mathrm{~dB} Z$ ) do not indicate low signal-to-noise ratio 


\section{$\operatorname{KEAX} 12.5^{\circ}$}

\section{Feb 2014}
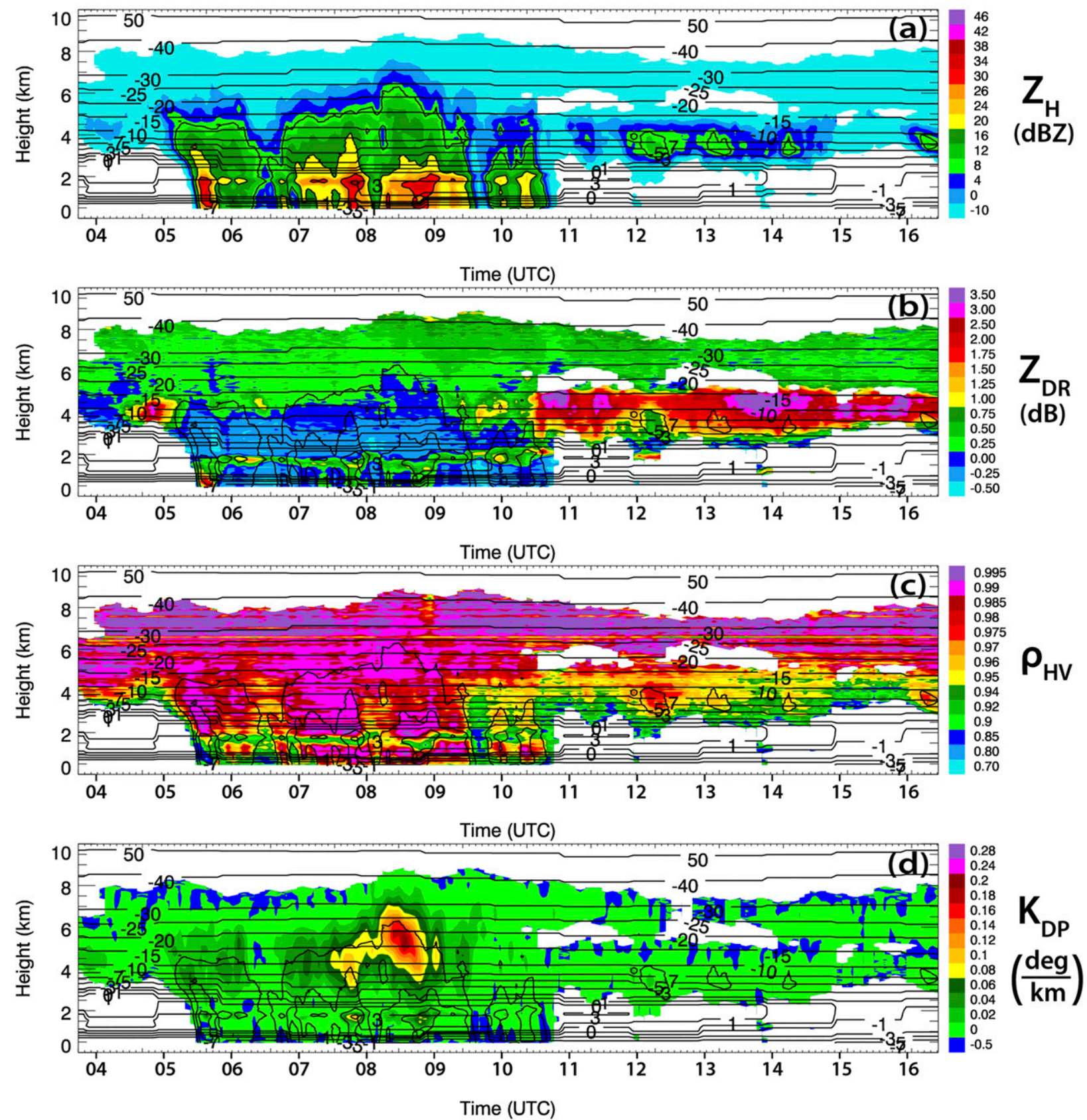

FIG. 3. QVPs of (a) $Z_{H}$, (b) $Z_{\mathrm{DR}}$, (c) $\rho_{\mathrm{HV}}$, and (d) $K_{\mathrm{DP}}$, for KEAX from 0353 through $1630 \mathrm{UTC} 1 \mathrm{Feb} 2014$, at $12.5^{\circ}$ elevation. Contours of HRRR model wet-bulb temperature $\left({ }^{\circ} \mathrm{C}\right)$ are overlaid in each plot. Also, $Z_{H}$ is contoured at $10,20,30$, and $40 \mathrm{dBZ}$.

(SNR), which affects the accuracy of $Z_{\mathrm{DR}}$ estimates. Indeed, the WSR-88D is a sensitive radar with minimal $Z_{H}$ from approximately -10 to $-11 \mathrm{~dB} Z$ (corresponding to $\mathrm{SNR}=0 \mathrm{~dB}$ ) reliably measured at the distance of $50 \mathrm{~km}$ from the radar. Because of the use of high elevation angles (between $10^{\circ}$ and $20^{\circ}$ ) for generating
QVPs, slant ranges at which most important polarimetric radar signatures within the DGL are observed are significantly smaller than $50 \mathrm{~km}$, which means the SNR values are well above $0 \mathrm{~dB}$. Additionally, noise powers in the orthogonal $\mathrm{H}$ and $\mathrm{V}$ channels are measured very accurately at each individual radial following 


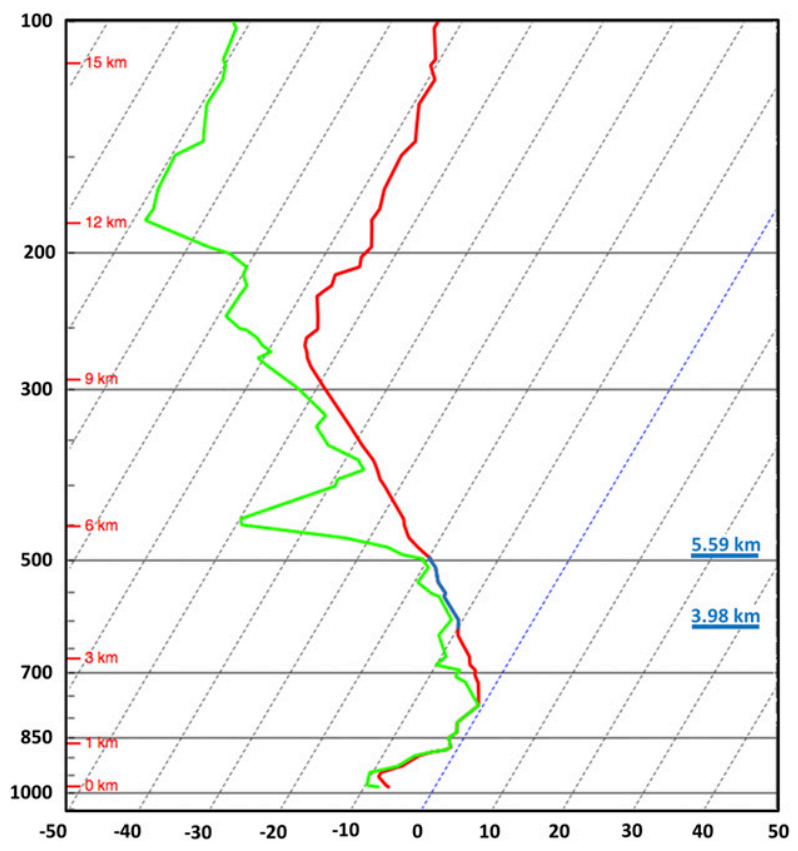

FIG. 4. SHARPpy thermodynamic sounding (Blumberg et al. 2017) for Topeka at 1200 UTC 1 Feb 2014, located approximately $120 \mathrm{~km}$ from KEAX. The red line represents temperature $\left({ }^{\circ} \mathrm{C}\right)$, the green line represents dewpoint temperature $\left({ }^{\circ} \mathrm{C}\right)$, and the blue solid lines indicate the location of the interpreted DGL $(\mathrm{km})$.

the methodology of Ivic et al. (2013), which allows accurate estimates of $Z_{\mathrm{DR}}$ and $\rho_{\mathrm{hv}}$ at low SNR.

\section{b. KOKX winter storm (pure snow case): 23 January 2016}

Strong $K_{\mathrm{DP}}$ signatures are also found in pure snow cases. As an example, we present $19.5^{\circ}$-elevation QVPs from the KOKX (Upton, New York) radar for the Northeast U.S. winter event on 23 January 2016, which produced heavy snow with accumulations up to $50.8 \mathrm{~cm}$ (NWS 2016). The precipitation structure of this pure snow case exhibits a different appearance than the transitional event structures. For example, $Z_{H}$ contours appear more slanted (Fig. 5a) and, as expected, there is an absence of a ML signature (e.g., Fig. 5c). As with the KEAX event, maximum $K_{\mathrm{DP}}$ in the DGL occurs during the periods of tallest and coldest cloud tops, more specifically from 1020 through 1320 UTC and from 1845 through 2130 UTC, with cloud top up to 10 and $8 \mathrm{~km}$ (at $-50^{\circ}$ and $-40^{\circ} \mathrm{C}$, respectively; Figs. 5a,d). From approximately 1320 through 1830 UTC, cloud tops are shallowest and warmest, at about $6 \mathrm{~km}$ and from $-20^{\circ}$ to $-25^{\circ} \mathrm{C}$. Moreover, there is no pronounced enhancement of $Z_{\mathrm{DR}}$ within the cloud (Fig. 5b), while $K_{\mathrm{DP}}$ in the DGL is expectedly well pronounced, reaching magnitudes up to $0.29^{\circ} \mathrm{km}^{-1}$ within the deep snow layer
(Fig. 5d). These signatures suggest nucleation of pristine ice crystals at cloud top, and a resulting increase in ice concentration below. Although the increase of $Z_{\mathrm{DR}}$ in the DGL is not well pronounced during the period of low cloud top from 1320 until 1830 UTC, the drop of $\rho_{\mathrm{hv}}$ in the DGL is quite noticeable (Fig. 5c), which indicates the presence of very anisotropic ice particles.

\section{c. Southern U.S. winter storm: 11-12 February 2014}

This section presents polarimetric QVP results from the perspective of three radars located in the southeastern United States (KGWX, Columbus Air Force Base, Mississippi; KDGX, Jackson, Mississippi; KBMX, Birmingham, Alabama), during a transitional winter storm on 11-12 February 2014 that produced maximum ice and snow accumulations of 2 and $12.7 \mathrm{~cm}$ (NWS 2014a), respectively. The system subsequently progressed northeastward up the eastern coast, where it produced further historic ice, snow, and sleet accumulations over the Carolinas. In agreement with previously presented events, each of the three radars exhibit numerous examples of the correlation between CTT with maximum $Z_{\mathrm{DR}}$ and $K_{\mathrm{DP}}$ in the DGL, thereby providing an example that demonstrates spatial consistency of the polarimetric signatures over a large area within a single winter storm.

\section{1) KGWX 11 FEBRUARY 2014}

QVPs for the KGWX radar at $19.5^{\circ}$ elevation from 0102 through 1555 UTC 11 February 2014 are presented in Fig. 6. A notable excursion of the ML to the surface (Figs. 6b,c) from approximately 1000 through 1320 UTC is indicated by enhanced $Z_{\mathrm{DR}}$ (as large as $2 \mathrm{~dB}$ ) and reduced $\rho_{\mathrm{HV}}$ (as low as 0.8 ). The $Z_{\mathrm{DR}}$ profile (Fig. 6b) illustrates the most dramatic polarimetric signature during this period. From approximately 0700 through 0800 UTC and from 1220 through 1555 UTC, enhanced $Z_{\mathrm{DR}}$ from 1 to $>3.5 \mathrm{~dB}$ is seen in the DGL near the $-10^{\circ} \mathrm{C}$ isotherm, with $Z_{\mathrm{DR}}$ maxima of as much as $4.9 \mathrm{~dB}$ occurring just after 0700 and 1500 UTC during the periods of warmest and shallowest (as warm as approximately $-15^{\circ} \mathrm{C}$ at $5 \mathrm{~km}$ ) cloud top (i.e., at $Z_{H} \geq-10 \mathrm{dBZ}$ ). The enhanced values are also located within $Z_{H}$ around $-10 \mathrm{~dB} Z$, along the periphery of the detected radar echo. During the periods of maximum DGL $Z_{\mathrm{DR}}, K_{\mathrm{DP}}$ in the DGL is generally $<0.06^{\circ} \mathrm{km}^{-1}$, suggesting low concentrations of ice crystals. This is consistent with relatively low cloud tops, which were mostly below the $-30^{\circ} \mathrm{C}$ isotherm. Also, $\rho_{\mathrm{HV}}$ in the DGL ranges from 0.85 to 0.95 (Fig. 6c). The common notion that the depression of the cross-correlation coefficient is associated with the diversity of hydrometeor types within the radar resolution volume may not be 
KOKX $19.5^{\circ}$

\section{Jan 2016}
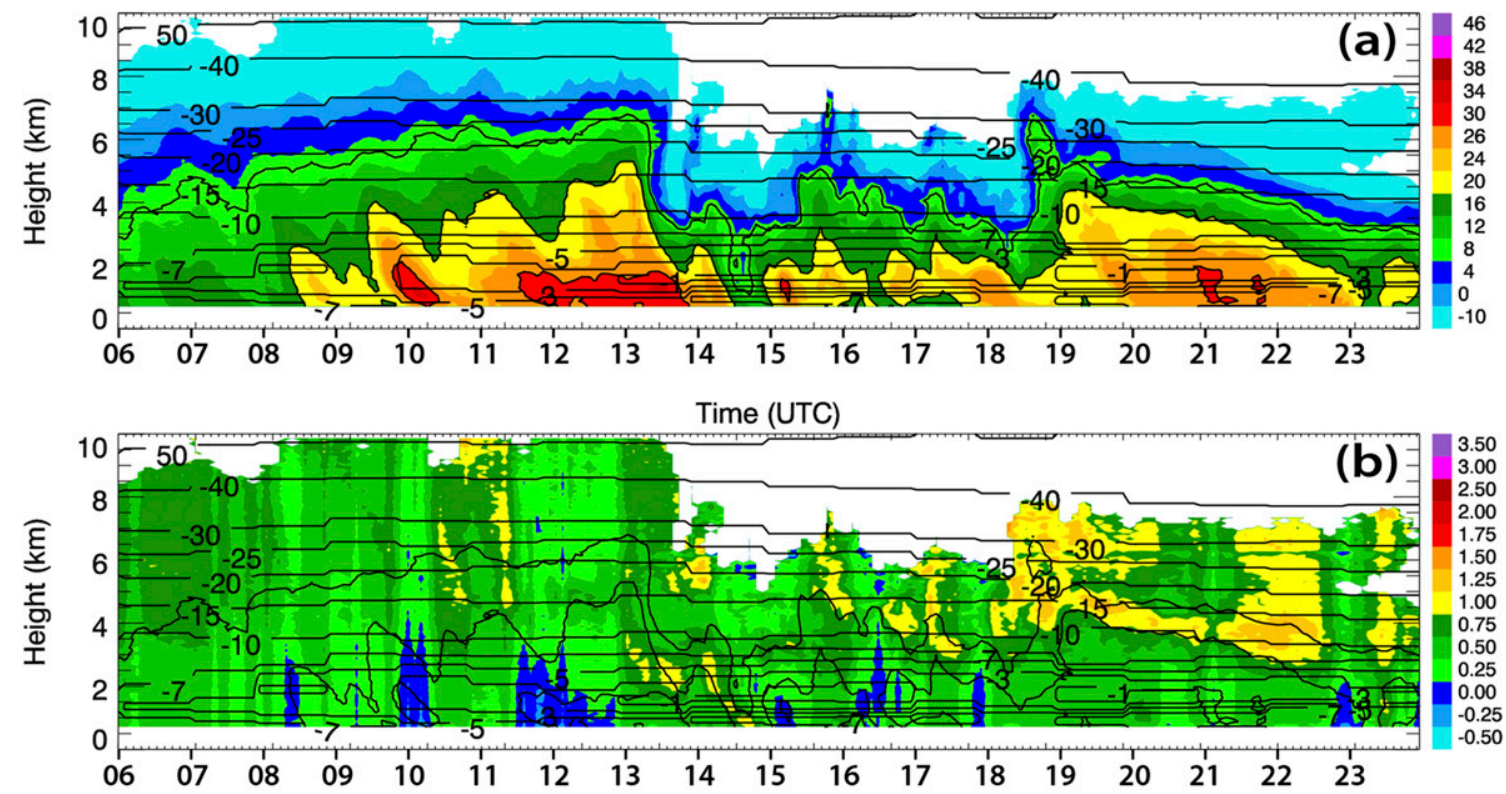

$\mathbf{Z}_{\mathrm{DR}}$

(dB)
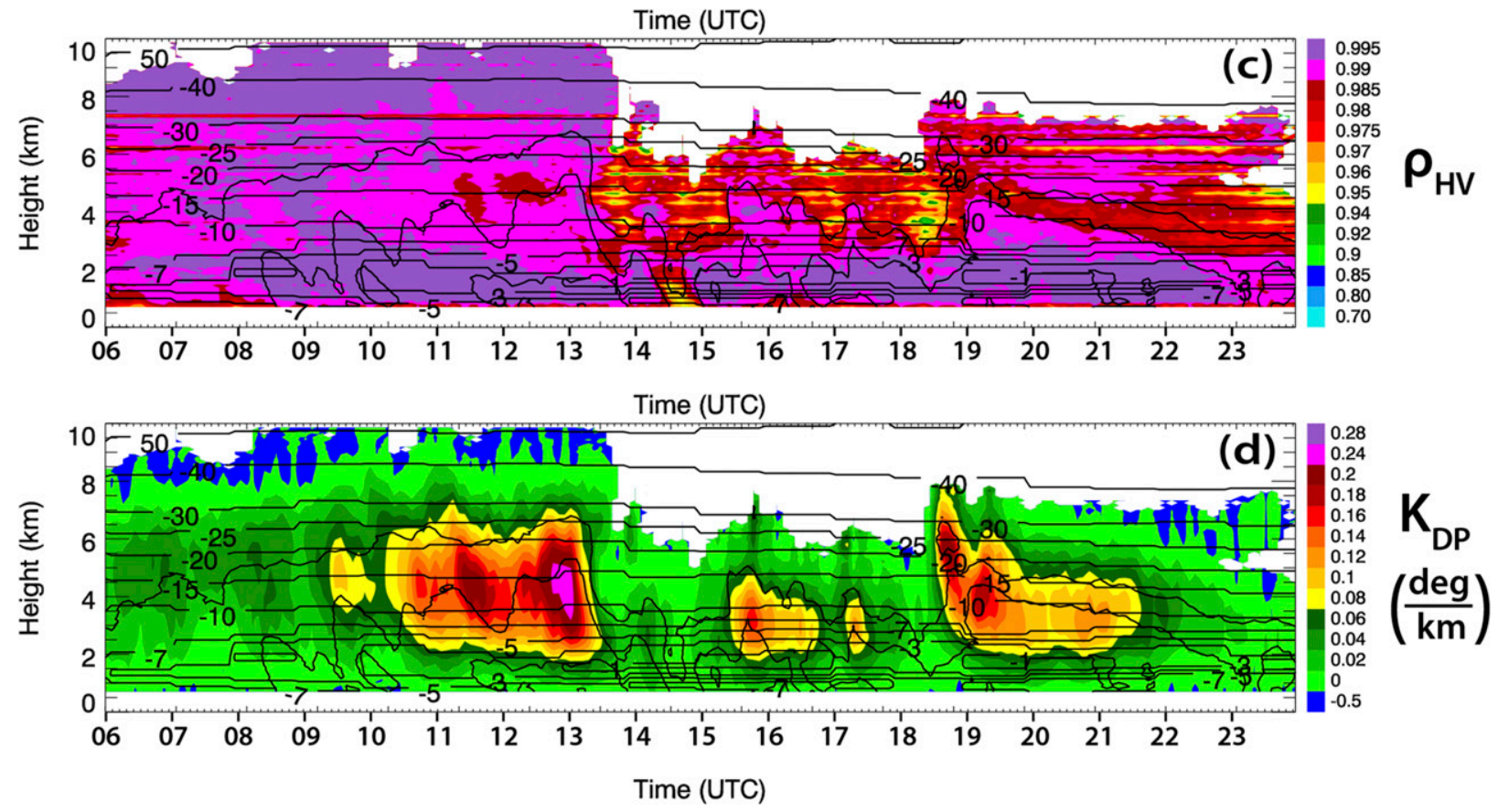

FIG. 5. As in Fig. 3, but for KOKX from 0600 through 2359 UTC 23 Jan 2016, at $19.5^{\circ}$ elevation.

necessarily applicable to the case of very anisotropic crystals with high $Z_{\mathrm{DR}}$ that are characterized by low $\rho_{\mathrm{hv}}$, although it might be only a single habit of ice particles (Melnikov and Straka 2013). The lowest values of $\rho_{\mathrm{hv}}$ in DGLs are always associated with the highest values of $Z_{\mathrm{DR}}$.
2) KBMX 12 FEBRUARY 2014

Figure 7 presents another example from the same winter system using $14.6^{\circ}$-elevation QVPs from the KBMX radar from 0119 through 2325 UTC 12 February 2014. Heavy snow and freezing rain were the predominant precipitation types observed at the surface, 
KGWX $19.5^{\circ}$

\section{Feb 2014}

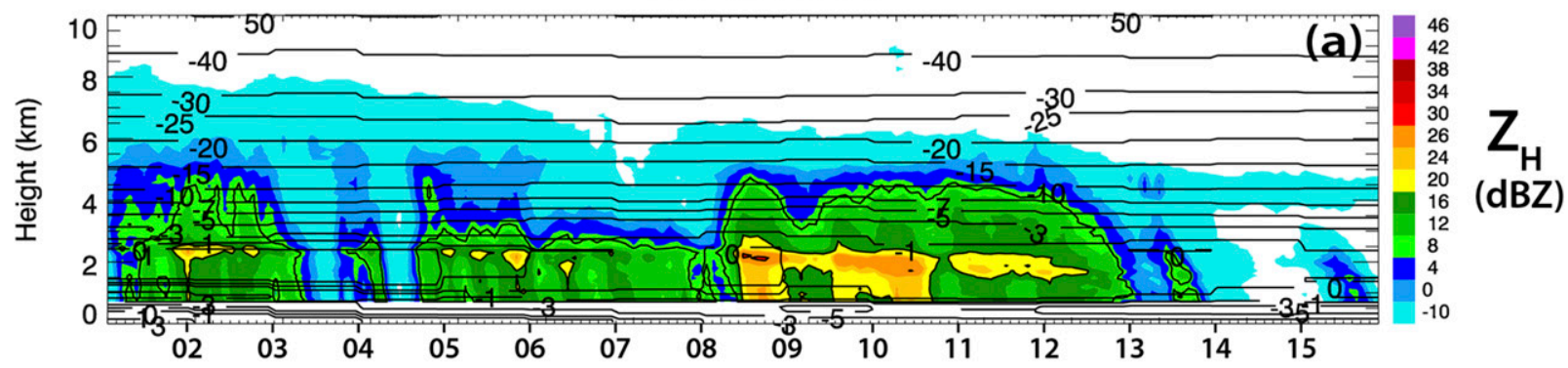

Time (UTC)

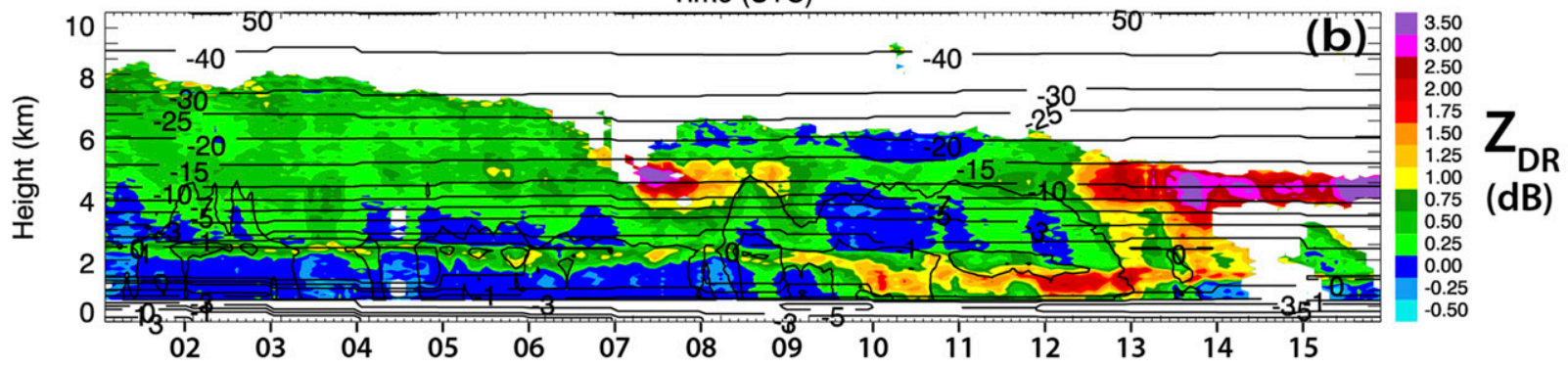

Time (UTC)

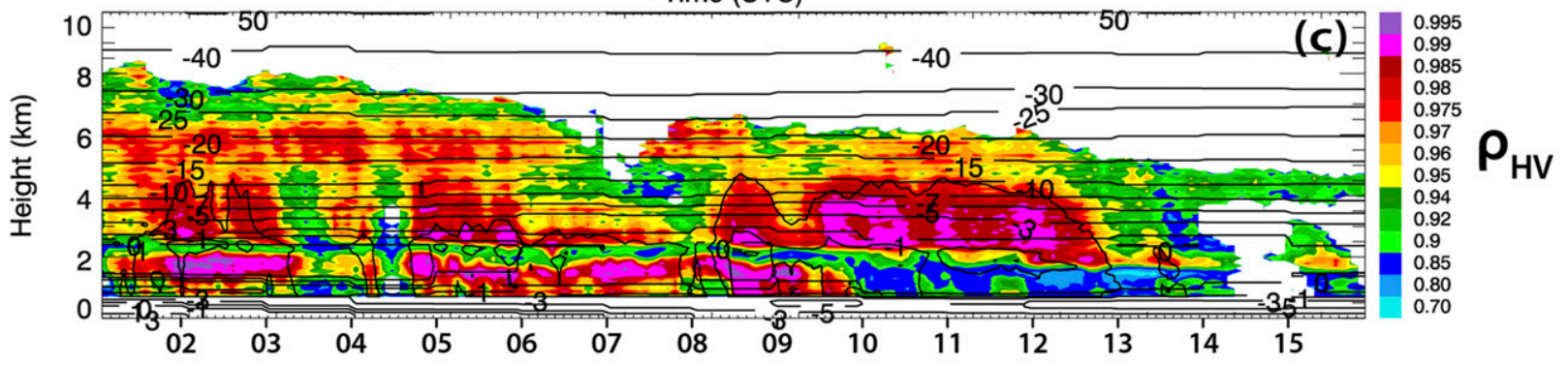

Time (UTC)

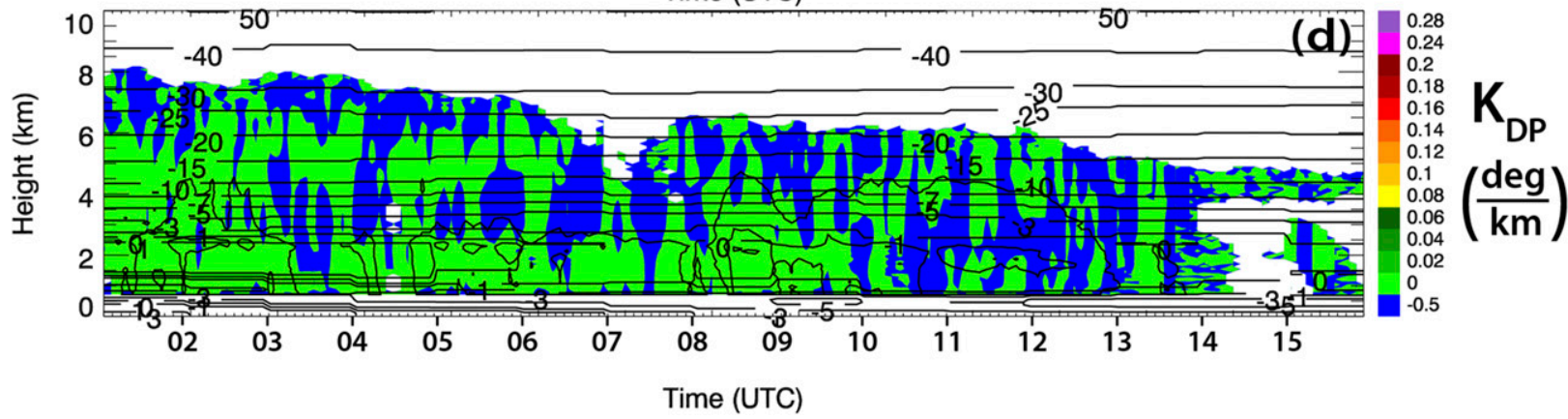

FIG. 6. As in Fig. 3, but for KGWX from 0102 through 1555 UTC $11 \mathrm{Feb} 2014$, at $19.5^{\circ}$ elevation.

with significant snow and ice accumulation up to 15.24 and $0.64 \mathrm{~cm}$, respectively (NWS 2014b). The QVPs provide another prominent example of the anticorrelation of maximum $K_{\mathrm{DP}}$ and maximum $Z_{\mathrm{DR}}$ in the DGL, as well as the correlation of those features with CTT. Maximum $K_{\text {DP }}$ in the DGL (up to $0.23^{\circ} \mathrm{km}^{-1}$ ) occurs from approximately 0430 through 0940 UTC in a layer from 3.5 to $7 \mathrm{~km}$, within $Z_{H}$ between 10 and $20 \mathrm{~dB} Z$, and above the largest $Z_{H}$ near the surface. The $K_{\text {DP }}$ maximum also occurs during the period of lowest $Z_{\mathrm{DR}}$ in the DGL, when cloud top is tallest $(10 \mathrm{~km})$ and coldest $\left(<-40^{\circ} \mathrm{C}\right)$. Note that this event requires 
KBMX $14.6^{\circ}$

\section{Feb 2014}

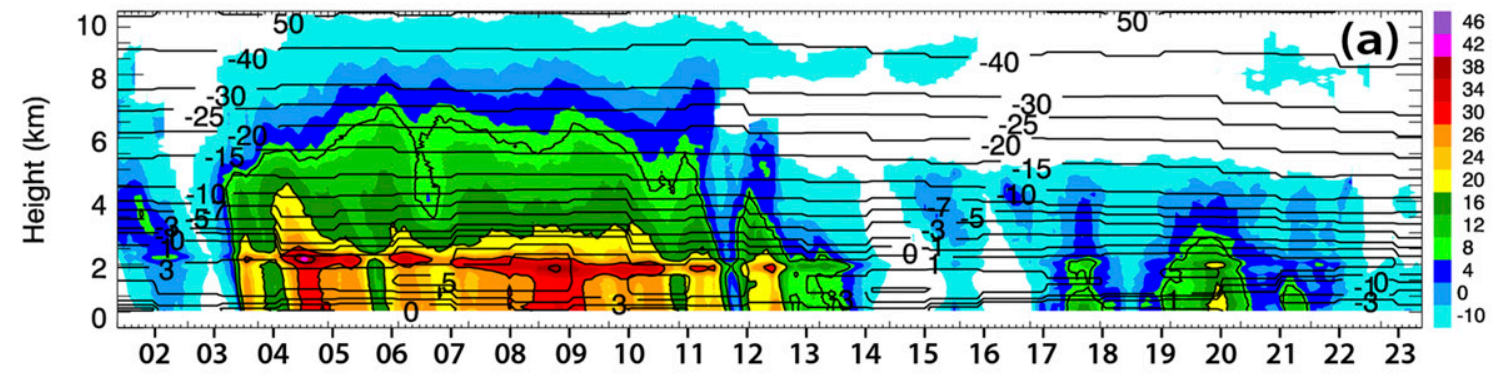

$\mathrm{Z}_{\mathrm{H}}$
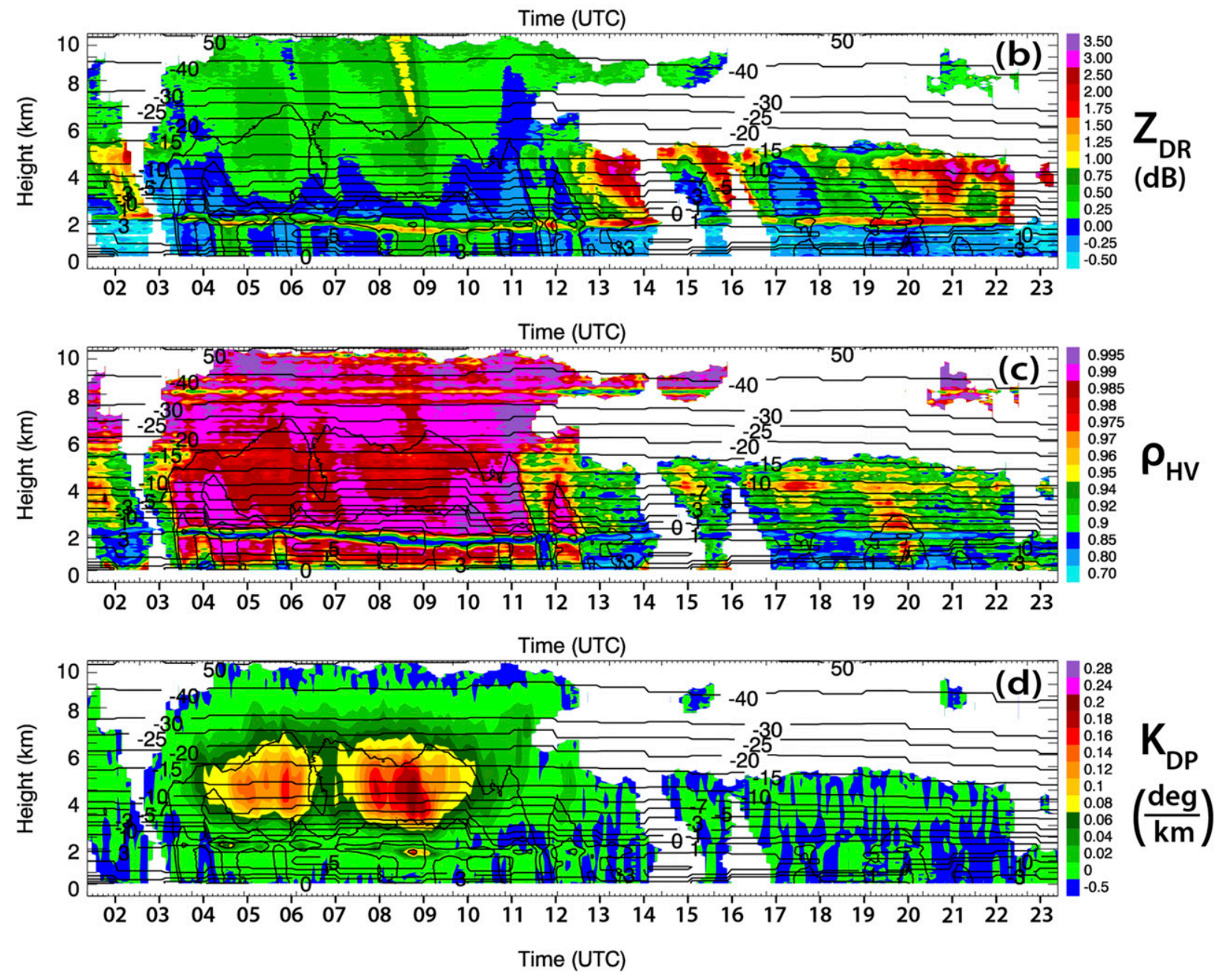

FIG. 7. As in Fig. 3, but for KBMX from 0119 through 2325 UTC 12 Feb 2014, at $14.6^{\circ}$ elevation.

additional criteria for defining cloud top because of minimal echoes above the main cloud top. To extract CTTs (with respect to microphysical analysis of the QVPs) for this event, the KBMX plots were processed in a similar manner to those of the KEAX event in section 3a, but with cloud top after 1231 UTC defined as the top of the echo beneath the midlevel layer of dry air, at approximately $5 \mathrm{~km}$.

After 1200 UTC, cloud top decreases in height to approximately $5 \mathrm{~km}$, near the $-15^{\circ} \mathrm{C}$ model-indicated isotherm, while $Z_{H}$ never exceeds $20 \mathrm{~dB} Z$ near the surface. During this period of shallower cloud top 
(i.e., from 1200 through $2325 \mathrm{UTC}$ ), $K_{\mathrm{DP}}$ in the DGL is very low, while $Z_{\mathrm{DR}}$ is enhanced and remains high within a layer between cloud top and the ML (i.e., between approximately 2 and $5 \mathrm{~km}$ ), with maximum values up to $4.3 \mathrm{~dB}$ within the DGL. The layer of enhanced $Z_{\mathrm{DR}}$, low $K_{\mathrm{DP}}$, and low $Z_{H}$ between cloud top and the ML indicates a low concentration of crystals that are generated in the DGL and fall into the ML without being aggregated, so that $Z_{\mathrm{DR}}$ remains high (Fig. 7b). Anisotropic, high-density ice crystals acquire water coating while falling through the ML and produce very high $Z_{\mathrm{DR}}$ combined with almost nonexistent brightband enhancement of $Z_{H}$ because of low concentration of ice particles and their small sizes.

\section{3) KDGX 12 February 2014}

A final example from the same southeastern U.S. winter storm event is from the KDGX radar, which produced a variety of precipitation types at the surface, including rain and freezing rain (ASOS). Figure 8 illustrates the $10^{\circ}$ elevation KDGX QVPs from 0006 through 1500 UTC 12 February 2014. As with the other radars presented for this system, these plots provide an exceptional example of anticorrelated maximum $K_{\mathrm{DP}}$ and maximum $Z_{\mathrm{DR}}$ in the DGL, as well as the correlation of those features with CTT. One of the most dramatic signatures is found in the $K_{\mathrm{DP}}$ profile (Fig. 8d). Maximum $K_{\mathrm{DP}}$ in the DGL reaches $0.3^{\circ} \mathrm{km}^{-1}$ from approximately 0200 through 0320 UTC in a layer from approximately 4 to $7 \mathrm{~km}$, within $Z_{H}$ between approximately 10 and $20 \mathrm{~dB} Z$, and above the largest $Z_{H}$ near the surface. The $K_{\mathrm{DP}}$ maximum also occurs during the period of lowest $Z_{\mathrm{DR}}$ in the DGL, when cloud tops are tallest and coldest (at approximately $10 \mathrm{~km}$ and $<-40^{\circ} \mathrm{C}$, respectively; Figs. $8 \mathrm{~b}, \mathrm{~d}$ ). During this period, enhanced $Z_{\mathrm{DR}}$ of approximately $1-1.75 \mathrm{~dB}$ and $\rho_{\mathrm{HV}}$ near unity in the upper region of the cloud indicates nucleation of pristine crystals within the coldest temperatures aloft, with maximum $K_{\mathrm{DP}}$ suggesting a resultant increase in ice concentration in the DGL.

After the period of tallest cloud-top height and largest $Z_{H}$ near the surface, cloud-top height drops to approximately $5 \mathrm{~km}$, near the $-15^{\circ} \mathrm{C}$ isotherm, after approximately 1150 UTC. From 1150 through 1500 UTC, cloud-top height is the shallowest during the event, while $K_{\mathrm{DP}}$ in the DGL is reduced to approximately $0^{\circ} \mathrm{km}^{-1}$ and $Z_{\mathrm{DR}}$ is noticeably enhanced between 3 and $5 \mathrm{~km}$, between the $-7^{\circ}$ and $-15^{\circ} \mathrm{C}$ isotherms. Reflectivity $Z_{\mathrm{DR}}$ within this layer reaches a maximum of $4.3 \mathrm{~dB}$, within $\rho_{\mathrm{HV}}$ from 0.9 to 0.95 and $Z_{H}$ from -10 to $0 \mathrm{~dB} Z$, suggesting the generation of pristine ice crystals in this region. The layer of enhanced $Z_{\mathrm{DR}}$, low $K_{\mathrm{DP}}$, and low $Z_{H}$ between cloud top and the
ML indicates the crystals grow quickly and fall toward the surface and into the ML, without being aggregated. The $Z_{\mathrm{DR}}$ is noticeably enhanced in the ML directly below this layer, indicating water-coating of the crystals as they begin to melt. Overall, this event further exhibits the consistency of the polarimetric features observed in the previous winter cases.

\section{Statistical analysis}

To quantify the above QVP results, 90th-percentile maximum $Z_{\mathrm{DR}}$ in the DGL (i.e., between $-10^{\circ}$ and $-20^{\circ} \mathrm{C}$ ), 90th-percentile maximum $K_{\mathrm{DP}}$ in the DGL, and 90th-percentile maximum $Z_{H}$ in the DGL are computed (in this section referred to as maximum $Z_{\mathrm{DR}}$, $K_{\mathrm{DP}}$, and $Z_{H}$, respectively). Scatterplots are then generated to compare the relationships between these variables, as well as between the polarimetric variables and CTT. Using values within the 90th percentile ensures a good representation of the largest values in the layer, without being skewed by any extreme values.

Figure 9 depicts a composite of each of the scatterplots from the winter event QVPs described in section 3. Overall, the datasets for each event in each of the scatterplots align well, with particularly close agreement in the CTT versus maximum $Z_{\mathrm{DR}}$ in the DGL (Fig. 9a), maximum $Z_{\mathrm{DR}}$ in the DGL versus maximum $K_{\text {DP }}$ in the DGL (Fig. 9e), and maximum $Z_{H}$ in the DGL versus maximum $K_{\mathrm{DP}}$ in the DGL (Fig. 9d) plots. The plot of CTT versus maximum $Z_{\mathrm{DR}}$ in the DGL (Fig. 9a) reveals two distinct clusters of values indicating moderate-to-high $Z_{\mathrm{DR}}$ (up to $6 \mathrm{~dB}$ ) during warmer CTT between approximately $-25^{\circ}$ and $-10^{\circ} \mathrm{C}$, and low $Z_{\mathrm{DR}}$ (approximately 0-2 dB) during colder CTT of approximately $<-25^{\circ} \mathrm{C}$. Conversely, CTT versus maximum $K_{\mathrm{DP}}$ in the DGL (Fig. 9b) demonstrates two clusters of data indicating generally larger $K_{\mathrm{DP}}$ (approximately $0^{\circ}-0.3^{\circ} \mathrm{km}^{-1}$ ) during colder CTT from approximately $-30^{\circ}$ to $-55^{\circ} \mathrm{C}$, and lower $K_{\mathrm{DP}}$ (from approximately $-0.1^{\circ}$ to $0.1^{\circ} \mathrm{km}^{-1}$ ) during warmer CTT from approximately $-30^{\circ}$ to $-10^{\circ} \mathrm{C}$.

Additionally, Fig. $9 \mathrm{c}$ demonstrates that larger maximum $Z_{\mathrm{DR}}$ in the DGL occurs within lower $Z_{H}$, with larger $Z_{\mathrm{DR}}$ of approximately $1-5.5 \mathrm{~dB}$ within $Z_{H}$ between -10 and $10 \mathrm{~dB} Z$, and $Z_{\mathrm{DR}}$ between approximately 0 and $1.5 \mathrm{~dB}$ within $Z_{H}$ of approximately $0-30 \mathrm{~dB} Z$. Figure $9 \mathrm{~d}$ demonstrates a tight cluster of data points, distinctly indicating that for each of the QVP events, larger maximum $K_{\mathrm{DP}}$ occurs within greater $Z_{H}$ in the DGL (strong positive correlation), with $K_{\mathrm{DP}}$ of approximately $0.05^{\circ}-0.3^{\circ} \mathrm{km}^{-1}$ corresponding to $Z_{H}$ between approximately 10 and $30 \mathrm{~dB} Z$, and $K_{\mathrm{DP}}$ from $-0.05^{\circ}$ to $0.1^{\circ} \mathrm{km}^{-1}$ corresponding to $Z_{H}$ between -10 and $10 \mathrm{~dB} Z$. In other words, larger 


\section{KDGX $10^{\circ}$}

\section{Feb 2014}
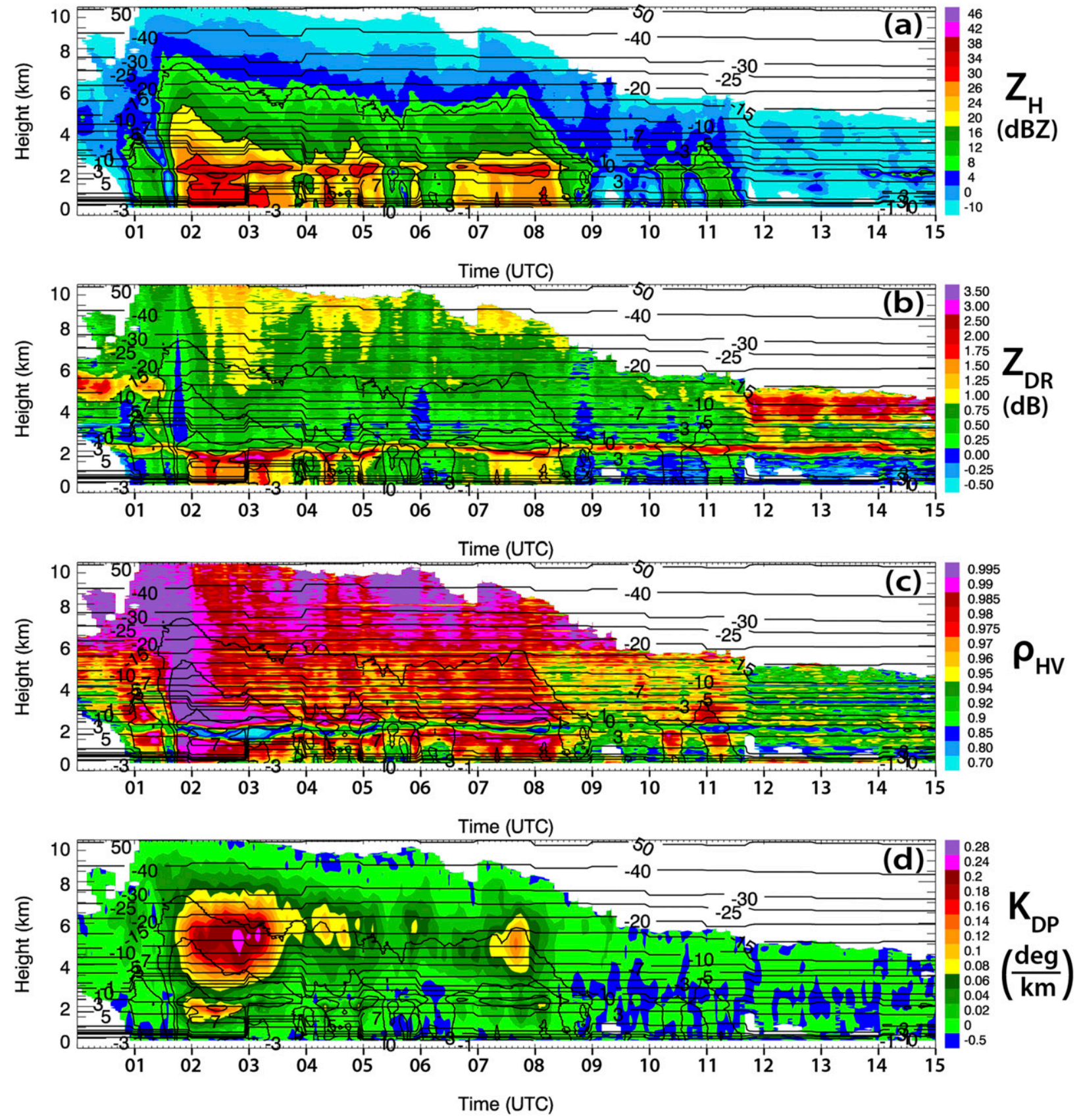

FIG. 8. As in Fig. 3, but for KDGX from 0006 through 1500 UTC 12 Feb 2014, at $10^{\circ}$ elevation.

maximum $Z_{\mathrm{DR}}$ occurs within lower $Z_{H}$, while larger maximum $K_{\mathrm{DP}}$ occurs within greater $Z_{H}$ in the DGL. Furthermore, Fig. 9e illustrates distinct anticorrelation of maximum $Z_{\mathrm{DR}}$ in the DGL versus maximum $K_{\mathrm{DP}}$ in the DGL, with larger $K_{\mathrm{DP}}$ from approximately $-0.05^{\circ}$ to $0.3^{\circ} \mathrm{km}^{-1}$ corresponding to $Z_{\mathrm{DR}}$ of approximately $0-1.5 \mathrm{~dB}$, and larger $Z_{\mathrm{DR}}$ of approximately $1-5 \mathrm{~dB}$ corresponding to $K_{\mathrm{DP}}$ between approximately $-0.05^{\circ}$ and $0.05^{\circ} \mathrm{km}^{-1}$.

Overall, the data from the winter events reveal several trends. There is ample evidence of the repetitiveness of anticorrelation of $Z_{\mathrm{DR}}$ and $K_{\mathrm{DP}}$ in the DGL, with the polarimetric variables strongly correlated with CTT. The $Z_{\mathrm{DR}}$ in the DGL is most pronounced and $K_{\mathrm{DP}}$ in the 

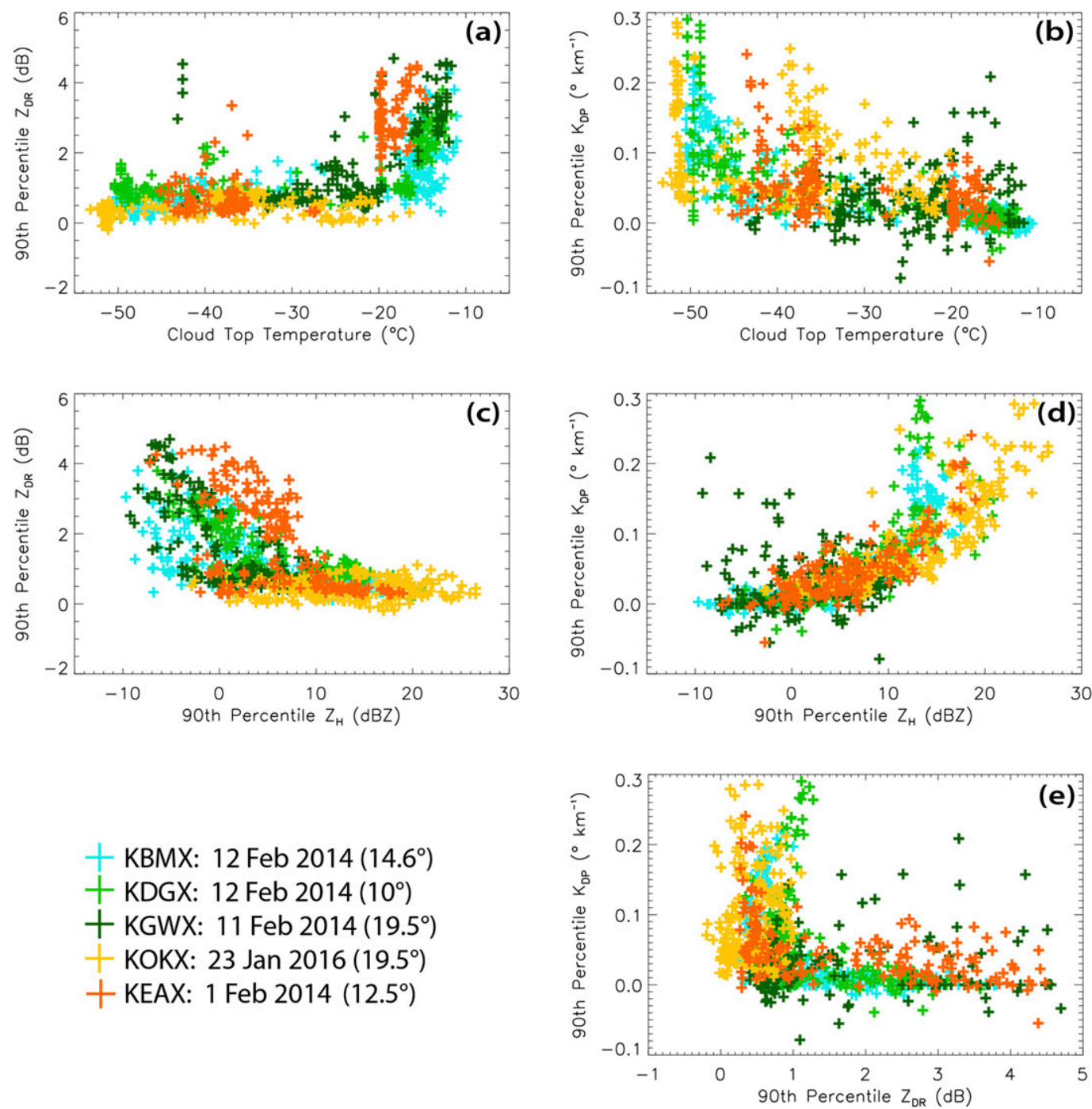

FIG. 9. Composite scatterplots of CTT $\left({ }^{\circ} \mathrm{C}\right)$ vs 90 th-percentile maximum (a) $Z_{\mathrm{DR}}$ and (b) $K_{\mathrm{DP}}$ in the DGL, 90 thpercentile maximum $Z_{H}$ in the DGL vs 90 th-percentile maximum (c) $Z_{\mathrm{DR}}$ and (d) $K_{\mathrm{DP}}$ in the DGL, and (e) 90 thpercentile maximum $Z_{\mathrm{DR}}$ in the DGL vs 90th-percentile maximum $K_{\mathrm{DP}}$ in the DGL. Data from the KBMX, KDGX, KGWX, KOKX, and KEAX events are indicated by the light-blue, light-green, dark-green, yellow, and orange symbols in each plot, respectively.

DGL is least pronounced during the shallowest and warmest cloud tops, while the opposite is true during the tallest and coldest cloud tops. These events also demonstrate that larger $Z_{\mathrm{DR}}$ in the DGL generally occurs within lower $Z_{H}$, while larger $K_{\mathrm{DP}}$ typically occurs within greater $Z_{H}$ in the DGL.

\section{Discussion}

\section{a. Interpretation of ice microphysical processes}

The results of the observations can be tentatively explained using the concept of two primary habits of ice particles with distinct polarimetric radar characteristics.
The first includes a broad category of snow aggregates and ice crystals with irregular or nearly spherical shapes. This category comprises an overwhelming majority of ice particles in stratiform clouds, according to the observations of Korolev et al. (2000, 2003). Another category includes pristine dendrites, hexagonal plates, and needles, which have very anisotropic shape and higher density than ice particles in the first category. Schrom and Kumjian (2016) distinguish these two classes of ice particles as "isometric" (I type) and "dendritic" (D type) and we will use similar names for these two categories, although they are not completely accurate. Indeed, "isometric" ice cannot be considered purely 
spherical or isometric because its aspect ratio is usually close to 0.6, as claimed by Korolev and Isaac (2003), Matrosov et al. (2005a), and Hogan et al. (2012). This means that I-type ice can produce moderate $Z_{\mathrm{DR}}$ and quite significant $K_{\mathrm{DP}}$ (if the concentration of I-type ice is sufficiently high). The "dendrite" class includes highly oblate (dendrites or hexagonal plates) or prolate (needles) hydrometeors with aspect ratios as low as 0.01 or as high as 10 . These ice crystals can have extremely large $Z_{\mathrm{DR}}$ (up to $10 \mathrm{~dB}$ ) and tangible $K_{\mathrm{DP}}$ (if their concentration is sufficiently high). As opposed to the I-type crystals, which can be generated at any level in the full depth of a cloud, the D-type crystals are generated only in certain temperature ranges: from $-20^{\circ}$ to $-10^{\circ} \mathrm{C}$ for dendrites and hexagonal plates and between $-3^{\circ}$ and $-8^{\circ} \mathrm{C}$ for needles.

We suggest that the areas of high $Z_{\mathrm{DR}}$ are dominated by D-type ice, whereas the areas of high $K_{\mathrm{DP}}$ are overwhelmed with the I-type ice, which does not exclude the presence of D-type ice crystals as well. If the cloud top is high and cold, then a variety of ice habits can be generated as primary ice at the cloud tops, for example, in generating cells (Kumjian et al. 2014). Initial concentration of primary ice is determined by the concentrations of ice nuclei that strongly depend on temperature (DeMott et al. 2010; Bailey and Hallett 2009) or supercooled cloud droplets that undergo homogeneous ice nucleation for $T<-37^{\circ} \mathrm{C}$. In the latter case, the concentration of primary ice is particularly high. The I-type ice particles may grow slowly via deposition or aggregation (if their concentration and size are large enough) while they fall down to the top of the DGL at about $-20^{\circ} \mathrm{C}$. Within the DGL, their growth by deposition intensifies because of the increasing difference between the water vapor saturation pressures with respect to water and ice. This is a dominant process in the upper half of the DGL (Lo and Passarelli 1982). When a sufficient number of I-type particles reach larger size, then the aggregation process quickly takes over the deposition growth and becomes a dominant growth process in the lower part of the DGL (below the $-15^{\circ} \mathrm{C}$ level) and at lower altitudes down to the ML (Moisseev et al. 2015).

Once large isometric crystals/snowflakes fall through the DGL, they continue to grow as I-type ice without much change in their shape. However, small I-type crystals may serve as embryos of rapidly growing dendrites or plates (depending on the supersaturation with respect to ice) with very anisotropic shape (Chen and Lamb 1994; Sheridan et al. 2009). These D-type crystals grow much faster in the DGL than the isometric ones, because of their higher capacitance. In addition, they can grow to very large sizes because their residence time within the DGL is longer than that of the isometric crystals because of the difference in their terminal velocities (Schrom and Kumjian 2016). Chen and Lamb (1994) demonstrate that D-type crystals become more anisotropic during their growth and acquire extremely low aspect ratios, leading to very high values of $Z_{\mathrm{DR}}$ (up to $10 \mathrm{~dB}$, e.g., as supported by observations of $Z_{\mathrm{DR}}$ up to $5.5 \mathrm{~dB}$ in Figs. 3 and 11).

Polarimetric radar variables depend on the relative contributions of the I-type and D-type ice particles in the mixture. In the situations when the DGL is not heavily seeded by I-type crystals falling from above, the contribution of the D-type ice is not masked by the contribution of I-type ice to $Z_{\mathrm{DR}}$ and the resulting $Z_{\mathrm{DR}}$ is very high. This explains strong dependence of $Z_{\mathrm{DR}}$ in the DGL on the temperature at the cloud top, which determines the concentration and size of I-type ice. The $K_{\mathrm{DP}}$ is usually quite low there because the total concentration of ice is low. There is also a notable decrease of $\rho_{\mathrm{hv}}$ in areas of the DGL where $Z_{\mathrm{DR}}$ is particularly high, since the $\rho_{\mathrm{hv}}$ of very anisotropic crystals is usually lower than that of quasi-spherical hydrometeors.

If the cloud is deep and the amount of isometric ice seeding the DGL is large, the contribution of I-type ice dominates the contribution from D-type crystals generated locally. This is why $Z_{\mathrm{DR}}$ may not show any enhancement in the DGL and the overwhelming majority of ice particles have aspect ratios close to 0.6 , which is enough to produce very high values of $K_{\mathrm{DP}}$ (because of high overall concentration of ice) combined with very modest $Z_{\mathrm{DR}}$ that does not depend on the concentration. Moreover, the dominance of large-sized I-type ice may inhibit dendritic growth in the DGL completely because of strong competition of the D-type and I-type crystals for available water vapor.

Below the DGL, $Z_{H}$ rapidly increases and $Z_{\mathrm{DR}}$ and $K_{\mathrm{DP}}$ tend to decrease toward the ground as a result of aggregation. The decrease of $K_{\mathrm{DP}}$ is likely caused by 1 ) the decrease of the snowflake density in the process of aggregation, 2) more chaotic orientation of large-sized snowflakes (e.g., Hendry et al. 1976, 1987; Matrosov et al. 2005b; Melnikov and Straka 2013), and 3) the decrease of the contribution of the pristine, nonaggregated D-type crystals. $Z_{\mathrm{DR}}$ usually remains high at the altitudes between $-10^{\circ}$ and $0^{\circ} \mathrm{C}$, if $Z_{\mathrm{DR}}$ in the DGL is high and the cloud above the DGL is shallow (e.g., Figs. 3b, $6 \mathrm{~b}$, and $7 \mathrm{~b}$ ). This is attributed to very low concentration of ice, which inhibits aggregation.

Specific differential phase $K_{\mathrm{DP}}$ may exhibit a secondary maximum in the temperature interval between $-3^{\circ}$ and $-8^{\circ} \mathrm{C}$, where secondary ice production is possibly driven by the Hallett-Mossop process. This requires some presence of riming and results in a large number of 
splinters that rapidly grow as needles in this interval of temperatures. Although the present study did not observe this, the corresponding increase of $K_{\mathrm{DP}}$ and, sometimes, $Z_{\mathrm{DR}}$ is documented by Sinclair et al. (2016) and Giangrande et al. (2016).

\section{b. In situ verification of polarimetric $Q V P$ observations of hexagonal plates in the $D G L$}

Williams et al. (2013) recently documented airborne in situ microphysical measurements of a winter snowstorm that occurred on 28 February 2013 over the KBUF WSR$88 \mathrm{D}$ in Buffalo, New York. During their flight, they discovered rare evidence of hexagonal flat-plate crystals in horizontally expansive layers of low, mainly negative $Z_{H}$ and high $Z_{\mathrm{DR}}$ of $4-8 \mathrm{~dB}$, near the $-11^{\circ} \mathrm{C}$ isotherm (Williams et al. 2013). Figure 10 displays a selection of their in situ observations, taken from 1835 through 1839 UTC. During this period, they document a region of predominantly hexagonal plates in a positive $Z_{\mathrm{DR}}$ region with values between 0 and $6 \mathrm{~dB}$, with low $Z_{H}$ from -15 to $7 \mathrm{dBZ}$, and indications of riming on the plates due to rounded corners on several of the crystals.

To look into the same cloud from the QVP perspective, and to determine whether the polarimetric QVP methodology reveals the presence of these crystals, data were obtained for this case and used to generate the associated QVPs. Unfortunately, because of the volume coverage pattern (VCP) used during this event, radar data are only available at as high as the $4.5^{\circ}$ elevation angle. Nevertheless, even at $4.5^{\circ}$ we see a prominent display of high $Z_{\mathrm{DR}}$ in the layer the aircraft was flying in during this period. Figure 11 shows the KBUF QVPs for $Z_{H}$ and $Z_{\mathrm{DR}}$ at $4.5^{\circ}$ elevation from 1600 through 2020 UTC 28 February 2013, for comparison with the $Z_{\mathrm{DR}}$ and in situ observations in Fig. 10. The $Z_{\mathrm{DR}}$ QVP indeed displays values in the range of $0-5.5 \mathrm{~dB}$ in the DGL, between the $-10^{\circ}$ and $-15^{\circ} \mathrm{C}$ isotherms and during approximately 1800-1945 UTC. After inspection of the raw data, maximum values of up to $5.5 \mathrm{~dB}$ occurred near the $-11^{\circ} \mathrm{C}$ isotherm, during approximately $1837-1923$ UTC (Fig. 11), which is consistent with $Z_{\mathrm{DR}}$ associated with hexagonal plates. Furthermore, the maximum $Z_{\mathrm{DR}}$ values occur near the edge of the $-10-\mathrm{dB} Z Z_{H}$ threshold. Overall, the KBUF QVP data support the findings of hexagonal plates in the DGL by Williams et al. (2013), and also support our interpretation of the QVP results of the five winter events in the previous sections.

\section{Summary}

Investigating the polarimetric and thermodynamic characteristics of winter precipitation is necessary to further our understanding of the microphysical processes within winter storms, as well as to improve their representation in numerical models. This study implements a new QVP methodology to investigate the microphysical evolution and significance of intriguing polarimetric signatures and their statistical correlations, observed in a selection of winter events. QVPs of transitional stratiform and pure snow precipitation are analyzed at high elevation angles (i.e., $9.9^{\circ}-19.5^{\circ}$ ) using data from S-band WSR-88Ds, alongside their corresponding environmental thermodynamic HRRR model analyses. In particular, QVPs of $K_{\mathrm{DP}}$ are implemented to demonstrate their value in interpreting ice processes in the upper levels of storms. The radar data are examined in light of the thermodynamic environment within which they developed, to help deduce their relation to cloud-top temperature and to identify the types of crystals potentially present throughout the depth of the cloud.

Several fascinating and repetitive polarimetric signatures are observed in the $Z_{\mathrm{DR}}$ and $K_{\mathrm{DP}} \mathrm{QVPs}$, in the DGL and at the tops of clouds. The most striking feature is maximum $Z_{\mathrm{DR}}$ (up to $6 \mathrm{~dB}$ ) in the DGL that occurs near the edge of the $-10-\mathrm{dB} Z Z_{H}$ contour within low $K_{\mathrm{DP}}$ and during shallower and warmer cloud tops, while maximum $K_{\mathrm{DP}}$ (up to $0.3^{\circ} \mathrm{km}^{-1}$ ) in the DGL occurs within low $Z_{\mathrm{DR}}$ and during taller and colder cloud tops. Essentially, $Z_{\mathrm{DR}}$ and $K_{\mathrm{DP}}$ in the DGL are anticorrelated and depend on the temperature at the top of the cloud.

To quantify the QVP observations, 90th-percentile maximum $Z_{\mathrm{DR}}$ in the DGL, 90th-percentile maximum $K_{\mathrm{DP}}$ in the DGL, and 90th-percentile maximum $Z_{H}$ in the DGL were computed to analyze the relationships between these variables, as well as between the polarimetric variables and CTT. The data demonstrate the distinct correlations of CTT with $Z_{\mathrm{DR}}$ and $K_{\mathrm{DP}}$ signatures in DGLs. The statistics also show that larger $Z_{\mathrm{DR}}$ occurs within lower $Z_{H}$ in the DGL, while larger $K_{\mathrm{DP}}$ occurs within greater $Z_{H}$ in the DGL. QVP data are also analyzed and compared to in situ microphysical measurements collected by Williams et al. (2013). These datasets verify the ability of the QVP to detect the presence of hexagonal plate crystals within the DGL, demonstrating the veracity of using QVPs to evaluate ice microphysics in the upper regions of winter clouds.

The QVP results can be attributed to distinct polarimetric radar characteristics of isometric (I type) and dendritic (D type) ice particles. I-type particles include a broad category of snow aggregates and ice crystals with irregular or nearly spherical shapes and can result in moderate $Z_{\mathrm{DR}}$ and significant $K_{\mathrm{DP}}$ (if the concentration of isometric ice is sufficiently high). The D-type crystals are composed of highly oblate (dendrites or hexagonal plates) or prolate (needles) hydrometeors 
(a)
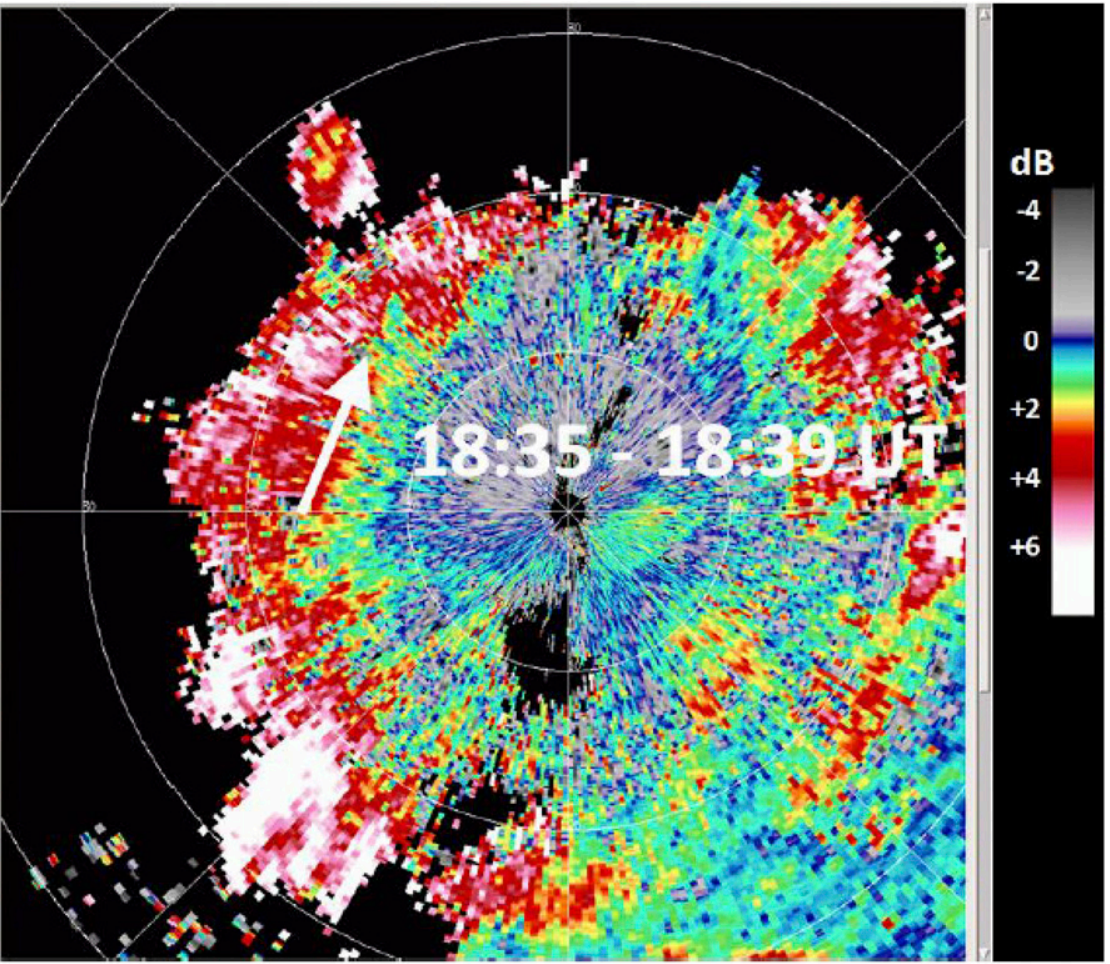

(b) P

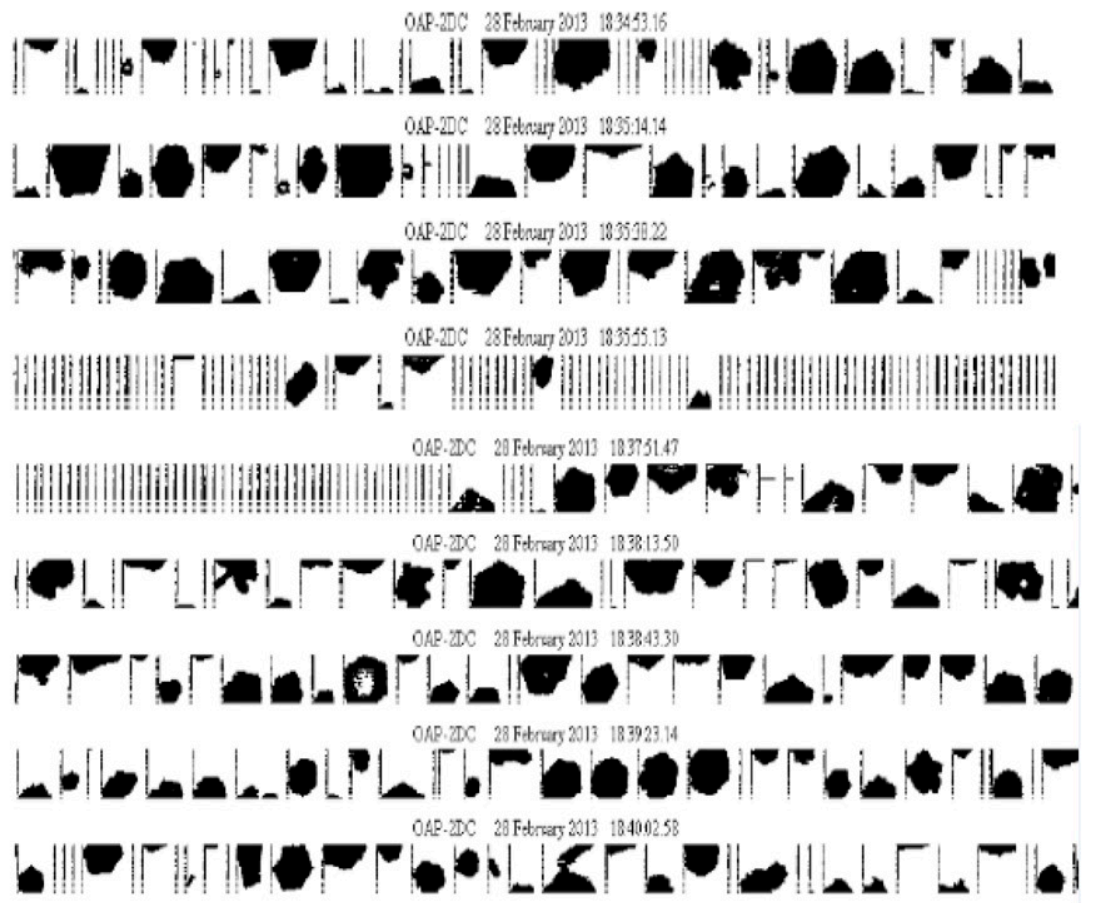

FIG. 10. (a) Reflectivity $Z_{\mathrm{DR}}$ at $2.5^{\circ}$ elevation angle with range ring labels spaced every $10 \mathrm{n} \mathrm{mi}$ $(18.52 \mathrm{~km})$. The white arrow indicates a segment of the aircraft trajectory during this period. (b) Iceparticle PMS 2DC imagery, with $25-\mu \mathrm{m}$ pixel resolution and $800-\mu \mathrm{m}$ spacing between vertical lines. During 1835-1839 UTC, hexagonal flat-plate crystals were found to be the predominant hydrometeor type, with corresponding $Z_{\mathrm{DR}}$ values of $0-6 \mathrm{~dB}$. The figure is adapted from Williams et al. (2013). 


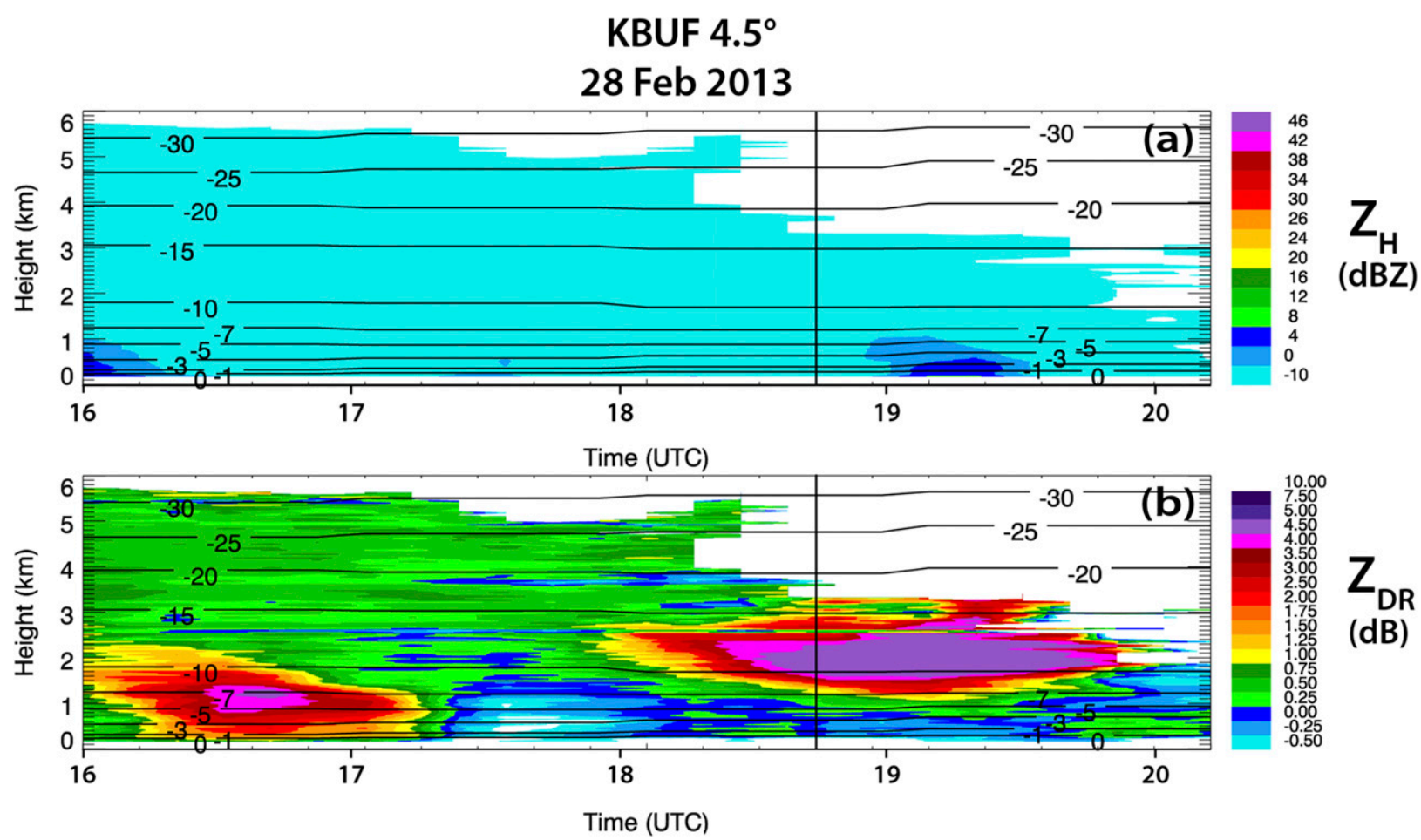

FIG. 11. QVPs of (a) $Z_{H}$ and (b) $Z_{\mathrm{DR}}$ for KBUF from 1600 through 2020 UTC $28 \mathrm{Feb} 2013$, at $4.5^{\circ}$ elevation. Contours of HRRR model wet-bulb temperature $\left({ }^{\circ} \mathrm{C}\right)$ are overlaid in each plot. Also, $Z_{H}$ is contoured at $10,20,30$, and $40 \mathrm{~dB} Z$. The vertical black lines indicate the flight time of the Williams et al. (2013) observations between approximately 1.5 and $2 \mathrm{~km}$, from 1835 through 1839 UTC. Note that the $Z_{\mathrm{DR}}$ scale is expanded to illustrate the maximum $Z_{\mathrm{DR}}$ values in this event and is different than the $Z_{\mathrm{DR}}$ scale used in the other figures.

that have very anisotropic shape and higher density than I-type ice particles. These ice crystals can exhibit extremely large $Z_{\mathrm{DR}}$ and tangible $K_{\mathrm{DP}}$ (if their concentration is sufficiently high; e.g., Fig. 5 illustrates enhanced $Z_{\mathrm{DR}}$ and $K_{\mathrm{DP}}$ between 1800 and 2100 UTC at approximately $5 \mathrm{~km}$ ). As opposed to the I-type crystals, which can be generated at any level in the full depth of a cloud, the D-type crystals are generated only in certain temperature ranges, with dendrites and hexagonal plates between $-20^{\circ}$ and $-10^{\circ} \mathrm{C}$ and needles between $-3^{\circ}$ and $-8^{\circ} \mathrm{C}$. We advocate that the regions of high $Z_{\mathrm{DR}}$ are dominated by D-type ice, whereas the regions of high $K_{\mathrm{DP}}$ are overwhelmed with the I-type ice, which does not exclude the presence of D-type ice crystals as well. Overall, the results of our analysis provide a next step toward advancing understanding of microphysical processes within winter clouds and precipitation, and demonstrate the value of QVPs in detecting key features in the upper regions of clouds.

Acknowledgments. The authors thank John Krause and Pengfei Zhang for instrumental advice and coding assistance in creating and improving the QVP plotting methodology. Funding was provided by the NOAA/ Office of Oceanic and Atmospheric Research under NOAA-University of Oklahoma Cooperative Agreement NA11OAR4320072, U.S. Department of Commerce, and by the U.S. National Weather Service, Federal Aviation Administration, and Department of Defense program for modernization of NEXRAD radars. Additional funding came from National Science Foundation Grant 1143948 and Department of Energy Grant DE-SC0008811. We also thank Valery Melnikov for helpful comments and suggestions for improving this manuscript.

\section{REFERENCES}

Andrić, J., M. R. Kumjian, D. S. Zrnić, J. M. Straka, and V. M. Melnikov, 2013: Polarimetric signatures above the melting layer in winter storms: An observational and modeling study. J. Appl. Meteor. Climatol., 52, 682-700, doi:10.1175/ JAMC-D-12-028.1.

Bailey, M. P., and J. Hallett, 2009: A comprehensive habit diagram for atmospheric ice crystals: Confirmation from the laboratory, AIRS II, and other field studies. J. Atmos. Sci., 66, 28882899, doi:10.1175/2009JAS2883.1.

Bechini, R., L. Baldini, and V. Chandrasekar, 2013: Polarimetric radar observations in the ice region of precipitating clouds 
at C-band and X-band radar frequencies. J. Appl. Meteor. Climatol., 52, 1147-1169, doi:10.1175/JAMC-D-12-055.1.

Benjamin, S., and Coauthors, 2016: A North American hourly assimilation and model forecast cycle: The Rapid Refresh. Mon. Wea. Rev., 144, 1669-1694, doi:10.1175/MWR-D-15-0242.1.

Blumberg, W. G., K. T. Halbert, T. A. Supinie, P. T. Marsh, R. L. Thompson, and J. A. Hart, 2017: SHARPpy: An open-source sounding analysis toolkit for the atmospheric sciences. Bull. Amer. Meteor. Soc., 98, 1625-1636, https://doi.org/10.1175/ BAMS-D-15-00309.1.

Chen, J., and D. Lamb, 1994: The theoretical basis for the parameterization of ice crystal habits: Growth by vapor deposition. J. Atmos. Sci., 51, 1206-1222, doi:10.1175/1520-0469 (1994)051<1206:TTBFTP>2.0.CO;2.

DeMott, P., and Coauthors, 2010: Predicting global atmospheric ice nuclei distributions and their impacts of climate. Proc. Natl. Acad. Sci. USA, 107, 11217-11222, doi:10.1073/ pnas.0910818107.

Doviak, R. J., and D. S. Zrnić, 1993: Doppler Radar and Weather Observations. 2nd ed. Academic Press, 562 pp.

Elmore, K. L., Z. L. Flamig, V. Lakshmanan, B. T. Kaney, V. Farmer, and L. P. Rothfusz, 2014: mPING: Crowd-sourcing weather reports for research. Bull. Amer. Meteor. Soc., 95, 1335-1342, doi:10.1175/BAMS-D-13-00014.1.

Giangrande, S., T. Toto, A. Bansemer, M. Kumjian, S. Mishra, and A. Ryzhkov, 2016: Insights into riming and aggregation processes as revealed by aircraft, radar, and disdrometer observations for a 27 April 2011 widespread precipitation event. J. Geophys. Res. Atmos., 121, 5846-5863, doi:10.1002/ $2015 J D 024537$.

Griffin, E. M., T. J. Schuur, A. V. Ryzhkov, H. D. Reeves, and J. C. Picca, 2014: A polarimetric and microphysical investigation of the northeast blizzard of 8-9 February 2013. Wea. Forecasting, 29, 1271-1294, doi:10.1175/WAF-D-14-00056.1.

Hendry, A., G. McCormick, and B. Barge, 1976: The degree of common orientations of hydrometeors observed by polarization diversity radars. J. Appl. Meteor., 15, 633-640, doi:10.1175/1520-0450(1976)015<0633:TDOCOO >2.0.CO;2.

_ - Y. Antar, and G. McCormick, 1987: On the relationship between the degree of preferred orientation in precipitation and dual-polarization radar echo characteristics. Radio Sci., 22, 37-50, doi:10.1029/RS022i001p00037.

Herzegh, P. H., and A. R. Jameson, 1992: Observing precipitation through dual-polarization radar measurements. Bull. Amer. Meteor. Soc., 73, 1365-1374, doi:10.1175/1520-0477(1992)073<1365: OPTDPR $>2.0 . \mathrm{CO} ; 2$.

Hogan, R., L. Tian, P. Brown, C. Westbrook, A. Heymsfield, and J. Eastment, 2012: Radar scattering from ice aggregates using the horizontally aligned oblate spheroid approximation. J. Appl. Meteor. Climatol., 51, 655-671, doi:10.1175/JAMC-D-11-074.1.

Ivic, I., C. Curtis, and S. Torres, 2013: Radial-based noise power estimation for weather radars. J. Atmos. Oceanic Technol., 30, 2737-2753, doi:10.1175/JTECH-D-13-00008.1.

Kaltenboeck, R., and A. Ryzhkov, 2017: A freezing rain storm explored with a C-band polarimetric weather radar using the QVP methodology. Meteor. Z., 26, 207-222, doi:10.1127/metz/ 2016/0807.

Kennedy, P. C., and S. A. Rutledge, 2011: S-band dual-polarization radar observations of winter storms. J. Appl. Meteor. Climatol., 50, 844-858, doi:10.1175/2010JAMC2558.1.

Korolev, A., and G. Isaac, 2003: Roundness and aspect ratio of particles in ice clouds. J. Atmos. Sci., 60, 1795-1808, doi:10.1175/1520-0469(2003)060<1795:RAAROP > 2.0.CO;2.
- - - and J. Hallett, 2000: Ice particle habits in stratiform clouds. Quart. J. Roy. Meteor. Soc., 126, 2873-2902, doi:10.1002/qj.49712656913.

,-- , S. Cober, J. Strapp, and J. Hallett, 2003: Microphysical characterization of mixed-phase clouds. J. Roy. Meteor. Soc., 129, 39-65, doi:10.1256/qj.01.204.

Kumjian, M. R., 2013a: Principles and applications of dualpolarization weather radar. Part I: Description of the polarimetric radar variables. J. Oper. Meteor., 1, 226-242, doi:10.15191/nwajom.2013.0119.

_ 2013b: Principles and applications of dual-polarization weather radar. Part II: Warm and cold season applications. J. Oper. Meteor., 1, 243-264, doi:10.15191/nwajom.2013.0120.

- 2013c: Principles and applications of dual-polarization weather radar. Part III: Artifacts. J. Oper. Meteor., 1, 265-274, doi:10.15191/nwajom.2013.0121.

— , and K. A. Lombardo, 2017: Insights into the evolving microphysical and kinematic structure of northeastern U.S. winter storms from dual-polarization Doppler radar. Mon. Wea. Rev., 145, 1033-1061, https://doi.org/10.1175/MWR-D15-0451.1.

, S. A. Rutledge, R. M. Rasmussen, P. C. Kennedy, and M. Dixon, 2014: High-resolution polarimetric radar observations of snow-generating cells. J. Appl. Meteor. Climatol., 53, 1636-1658, https://doi.org/10.1175/JAMC-D-13-0312.1.

Lo, K., and R. Passarelli, 1982: The growth of snow in winter storms: An airborne observational study. J. Atmos. Sci., 39, 697-706, doi:10.1175/1520-0469(1982)039<0697:TGOSIW>2.0.CO;2.

Matrosov, S., A. Heymsfield, and Z. Wang, 2005a: Dual-frequency radar ratio of nonspherical atmospheric hydrometeors. Geophys. Res. Lett., 32, L13816, doi:10.1029/2005GL023210.

, R. Reinking, and I. Djalalova, 2005b: Inferring fall attitudes of pristine dendritic crystals from polarimetric radar data. J. Atmos. Sci., 62, 241-250, doi:10.1175/JAS-3356.1.

Melnikov, V., and J. Straka, 2013: Axis ratios and flutter angles of cloud ice particles: Retrievals from radar data. J. Atmos. Oceanic Technol., 30, 1691-1703, doi:10.1175/ JTECH-D-12-00212.1.

Moisseev, D., S. Lautaportti, J. Tyynela, and S. Lim, 2015: Dualpolarization radar signatures in snowstorms: Role of snowflake aggregation. J. Geophys. Res. Atmos., 120, 12 644-12 665, doi:10.1002/2015JD023884.

NWS, 2014a: One for the history books, February 11-13, 2014. Peachtree City, GA, Weather Forecast Office, https://www. weather.gov/ffc/20140212_winterstorm.

_ , 2014b: Winter storm of February 12-13, 2014. Birmingham, AL, Weather Forecast Office, https://www.weather.gov/bmx/ winter_02122014.

_ 2016: Public information statement: Spotter reports. National Weather Service Raw Text Product, New York, NY, https:// mesonet.agron.iastate.edu/wx/afos/p.php?pil $=$ PNSOKX\&e $=$ 201601232204.

Rogers, R. R., and M. K. Yau, 1989: A Short Course in Cloud Physics. 3rd ed. Butterworth-Heinemann, 290 pp.

Ryzhkov, A. V., and D. S. Zrnić, 1998: Discrimination between rain and snow with a polarimetric radar. J. Appl. Meteor., 37, 1228-1240, doi:10.1175/1520-0450(1998)037<1228:DBRASW>2.0.CO;2.

, —_ , and B. A. Gordon, 1998: Polarimetric method for ice water content determination. J. Appl. Meteor., 37, 125-134, doi:10.1175/1520-0450(1998)037<0125:PMFIWC >2.0.CO;2.

, S. E. Giangrande, and T. J. Schuur, 2005: Rainfall estimation with a polarimetric prototype of WSR-88D. J. Appl. Meteor., 44, 502-515, doi:10.1175/JAM2213.1. 
P. Zhang, H. D. Reeves, M. R. Kumjian, T. Tschallener, S. Tromel, and C. Simmer, 2016: Quasi-vertical profiles-A new way to look at polarimetric radar data. J. Atmos. Oceanic Technol., 33, 551-562, doi:10.1175/JTECH-D-15-0020.1.

Schrom, R. S., and M. R. Kumjian, 2016: Connecting microphysical processes in Colorado winter storms with vertical profiles of radar observations. J. Appl. Meteor. Climatol., 55, 1771-1787, doi:10.1175/JAMC-D-15-0338.1.

,-- , and Y. Lu, 2015: Polarimetric radar signatures of dendritic growth zones within Colorado winter storms. J. Appl. Meteor. Climatol., 54, 2365-2388, doi:10.1175/JAMC-D-15-0004.1.

Sheridan, L., J. Harrington, D. Lamb, and K. Sulia, 2009: Influence of ice crystal aspect ratio on the evolution of ice size spectra during vapor depositional growth. J. Atmos. Sci., 66, 3732-3743, doi:10.1175/2009JAS3113.1.

Sinclair, V., D. Moisseev, and A. von Lerber, 2016: How dualpolarization radar observations can be used to verify model representation of secondary ice. J. Geophys. Res. Atmos., 121, 10 954-10 970,doi:10.1002/2016JD025381.

Smith, T. L., S. G. Benjamin, J. M. Brown, S. Weygandt, T. Smirnova, and B. Schwartz, 2008: Convection forecasts from the hourly updated, 3-km High Resolution Rapid Refresh (HRRR) model. 24th Conf. on Severe Local Storms, Savannah, GA, Amer. Meteor. Soc., 11.1, https://ams.confex. com/ams/pdfpapers/142055.pdf.

Straka, J. M., D. S. Zrnić, and A. V. Ryzhkov, 2000: Bulk hydrometeor classification and quantification using polarimetric radar data: Synthesis of relations. J. Appl.
Meteor., 39, 1341-1372, doi:10.1175/1520-0450(2000)039<1341: BHCAQU $>2.0 . \mathrm{CO} ; 2$.

Trömel, S., A. Ryzhkov, P. Zhang, and C. Simmer, 2014: Investigations of backscatter differential phase in the melting layer. J. Appl. Meteor. Climatol., 53, 2344-2359, doi:10.1175/ JAMC-D-14-0050.1.

Vivekanandan, J., V. N. Bringi, M. Hagen, and P. Meischner, 1994: Polarimetric radar studies of atmospheric ice particles. IEEE Trans. Geosci. Remote Sens., 32, 1-10, doi:10.1109/36.285183.

Williams, E. R., D. Smalley, M. Donovan, R. Hallowell, M. Wolde, M. Bastian, A. Korolev, and R. Evaristo, 2013: Validation of NEXRAD radar differential reflectivity measurements in snowstorms with airborne microphysical measurements: Evidence for hexagonal flat plate crystals. 36th Conf. on Radar Meteorology, Breckenridge, CO, Amer. Meteor. Soc., 15A.6, https://ams.confex.com/ams/36Radar/webprogram/Manuscript/ Paper228791/Williams_36RADAR_15A6.pdf. , and Coauthors, 2015: Measurements of differential reflectivity in snowstorms and warm season stratiform systems. J. Appl. Meteor. Climatol., 54, 573-595, doi:10.1175/ JAMC-D-14-0020.1.

Wolde, M., and G. Vali, 2001: Polarimetric signatures from ice crystals observed at $95 \mathrm{GHz}$ in winter clouds. Part I: Dependence on crystal form. J. Atmos. Sci., 58, 828-841, doi:10.1175/1520-0469(2001)058<0828:PSFICO >2.0.CO;2.

Zrnić, D. S., and A. V. Ryzhkov, 1999: Polarimetry for weather surveillance radars. Bull. Amer. Meteor. Soc., 80, 389-406, doi:10.1175/1520-0477(1999)080<0389:PFWSR>2.0.CO;2. 